\title{
An assessment of community-based family planning programs in Kenya
}

Jane Chege

Population Council

Ian Askew

Population Council

Follow this and additional works at: https://knowledgecommons.popcouncil.org/departments_sbsr-rh

Part of the International Public Health Commons, Maternal and Child Health Commons, and the Women's Health Commons

How does access to this work benefit you? Let us know!

\section{Recommended Citation}

Chege, Jane and lan Askew. 1997. "An assessment of community-based family planning programs in Kenya," Africa OR/TA Project II Final Report. Nairobi: Population Council. 


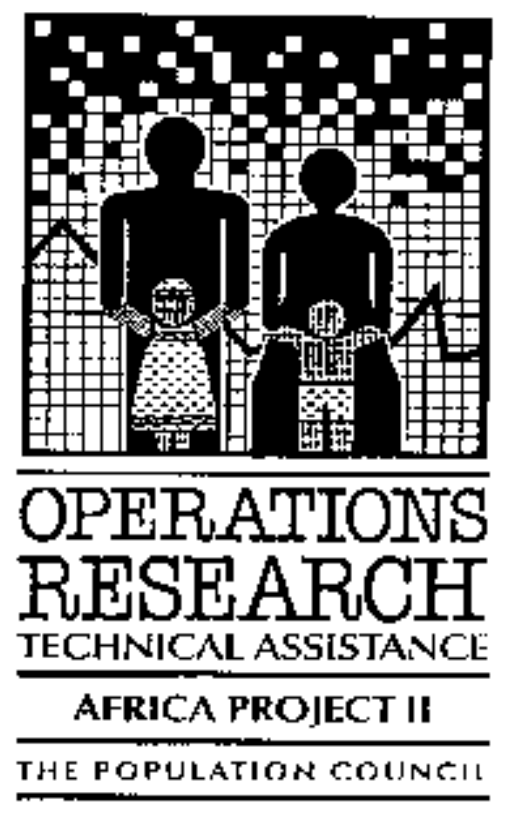

\section{AN ASSESSMENT OF COMMUNITY-BASED}

\section{FAMILY PLANNING PROGRAMMES}

\section{IN KENYA}

The Africa OR/TA Project II

The Population Council

Jane Njeri Chege

Ian Askew

January 1997 


\section{The Population Council}

The Population Council seeks to help improve the well-being and reproductive healthof current and future generations around the world and to help achieve a humane, equitable, and sustainable balance between people and resources. The Council analyzes population issues and trends; conducts biomedical research to develop new contraceptives; works with public and private agencies to improve the quality and outreach of family planning and reproductive health services; help governments to influence demographic behavior; communicate the results of research in the population field to appropriate audiences; and helps build research capacities in developing countries. The Council, a nonprofit, nongovernmental research organization established in 1952, has a multinational Board of Trustees; its New York headquarters supports a global network of regional and country offices.

\section{Africa OR/TA Project II}

The overall objectives of the Africa OR/TA Project II are to broaden understanding of how to improve family planning services in Sub-Saharan Africa, and to apply operations research and technical assistance to improve services by:

C increasing access to a full range of family planning services and methods;

C developing service delivery strategies that are client-oriented and acceptable to various population groups;

C improving the operations of programs to make them more efficient and financially sustainable;

C improving the quality of services;

C strengthening the capabilities of family planning program managers to use operations research to diagnose and solve service delivery problems.

This study was supported by The Population Council's Africa Operations Research and Technical Assistance Project II. The Africa OR/TA Project II is funded by the U.S. Agency for International Development (A.I.D), Office of Population, Contract No. CCC-3030-C-00-3008-00, Strategies for Improving Family Planning Service Delivery. 


\section{Acknowledgments}

This study is an outcome of a collaborative effort between The Population Council, FPAK, Maendeleo, NCC, MOH Division of Family Health, FLPS, CHAK, USAID, GTZ, Pathfinder International, CEDPA, and the National Council for Population and Development (NCPD). We express our sincere gratitude to the managers and staff of these organizations for their valuable support to the study. In particular, we would like to thank Maureen Kuyoh (FPAK), Margaret Waithaka (Maendeleo), Joyce Kinaro (NCC urban slum project), Hellen Wanjala (NCC), Dr. Achola Ominde (MOH), Mary Kairu (CEDPA), F. Maloba (CHAK), Dorcas Kungu (NCPD), Timothy Takona (USAID), Gilbert Magiri (Pathfinder), Nelson Keyonzo (Pathfinder) and Dr. Alan Ferguson (GTZ), who acted as the study's contact persons in their organizations.

In addition, we would like to thank our colleagues in USAID, the Africa OR/TA project and The Africa Population Policy Research Center for reviewing the study's proposal and draft reports. Special thanks to Professor Wang'ombe and Mercy Mugo of the University of Nairobi who assisted with the cost component of this study.

Last but not least, we appreciate the dedicated participation in the field work, of all the field supervisors, research assistants, interviewers, respondents and the field staff of all the CBD programmes and sites that participated in the study. 


$\begin{array}{lll}\text { AIDS } & - & \text { Acquired Immune Deficiency Syndrome } \\ \text { CBD } & - & \text { Community-Based Distribution } \\ \text { CEA } & - & \text { Cost Effectiveness Analysis } \\ \text { CEDPA } & - & \text { Center for Development and Population Activities } \\ \text { CHAK } & - & \text { Christian Health Association on Kenya } \\ \text { CPR } & - & \text { Contraceptive Prevalence Rate } \\ \text { DDB } & - & \text { Double Declining Balance } \\ \text { DFH } & - & \text { Division of Family Health } \\ \text { FLPS } & - & \text { Family Life Promotion and Services } \\ \text { FP } & - & \text { Family Planning } \\ \text { FPAK } & - & \text { Family Planning Association of Kenya } \\ \text { GTZ } & - & \text { German Technical Corporation (Deutsche Gesellsch Aft Für Technische } \\ & & \text { Zusammenarbeit) } \\ \text { HIV } & - & \text { Human Immunodeficiency Virus } \\ \text { IEC } & - & \text { Information, Education and Communication } \\ \text { KDHS } & - & \text { Kenya Demographic and Health Survey } \\ \text { MCH } & - & \text { Maternal-Child Healthcare } \\ \text { MOH } & - & \text { Ministry of Health } \\ \text { MYWO } & - & \text { Maendeleo Ya Wanawake Organization } \\ \text { NCCFP } & - & \text { Nairobi City Council Family Planning Project } \\ \text { NCCS } & - & \text { Nairobi City Council Slum Project } \\ \text { NCPD } & - & \text { National Council for Population and Development } \\ \text { NGOs } & - & \text { Non-Governmental Organizations } \\ \text { PHC } & - & \text { Primary Health Care } \\ \text { RTIs } & - & \text { Reproductive Tract Infections } \\ \text { SLD } & - & \text { Straight Line Depreciation } \\ \text { STD } & - & \text { Sexually Transmitted Diseases } \\ \text { STIs } & - & \text { Sexually Transmitted Infections } \\ \text { UNFPA } & - & \text { United Nations Population Fund } \\ \text { USAID } & - & \text { United States Agency for International Development } \\ & & \\ \text { NOS } & \end{array}$




\section{TABLE OF CONTENTS}

EXECUTIVE SUMMARY

I. BACKGROUND AND METHODOLOGY $\ldots \ldots \ldots \ldots \ldots \ldots \ldots \ldots \ldots \ldots \ldots$

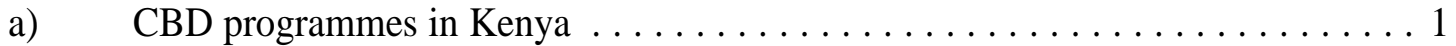

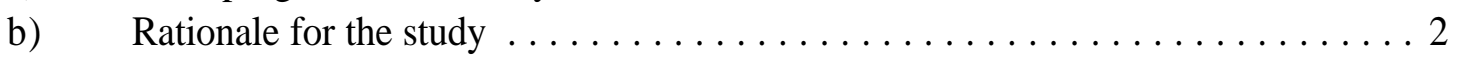

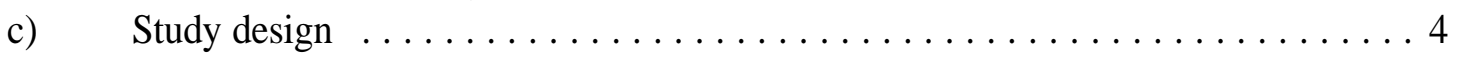

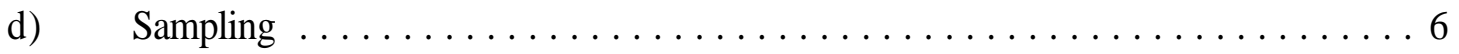

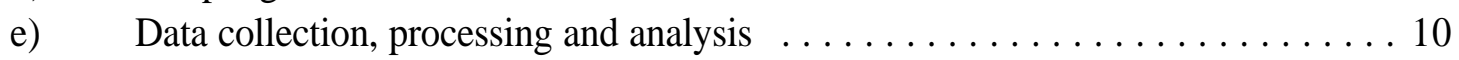

II. ROLE OF CBD AGENTS IN PROVIDING

FAMILY PLANNING INFORMATION AND SERVICES $\ldots \ldots \ldots \ldots \ldots \ldots 11$

a) Awareness among community members of CBD Agents $\ldots \ldots \ldots \ldots \ldots \ldots 11$

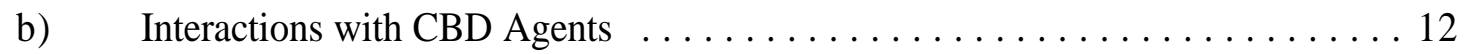

c) Role of CBD programmes in providing

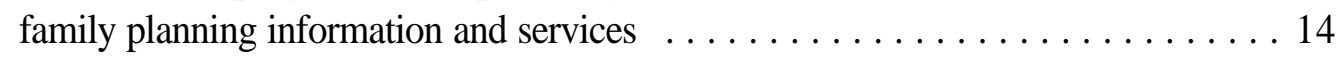

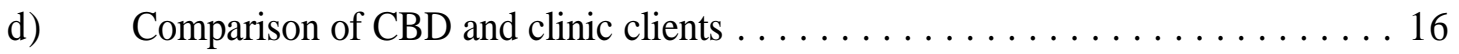

e) Provision of services to the youth and unmarried $\ldots \ldots \ldots \ldots \ldots \ldots \ldots$

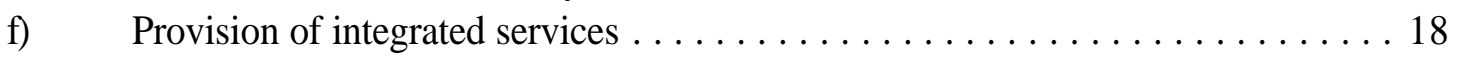

g) Impact of CBD work on female agent's life $\ldots \ldots \ldots \ldots \ldots \ldots \ldots \ldots \ldots$

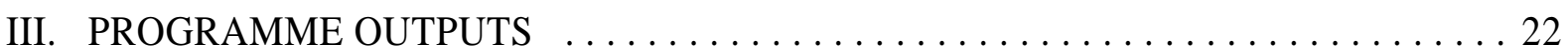

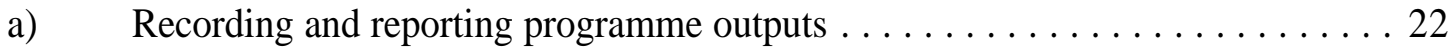

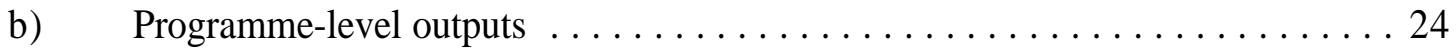

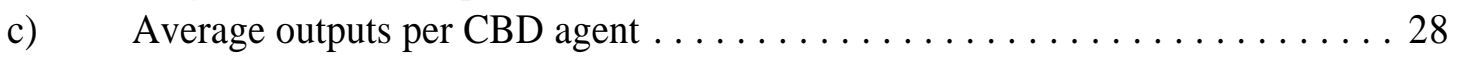
d) Comparative productivity of CBD and clinic programmes . . . . . . . 30

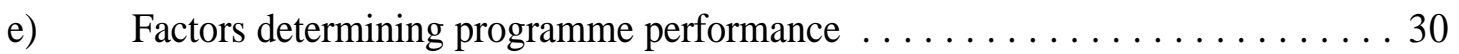

IV: COST AND COST-EFFECTIVENESS

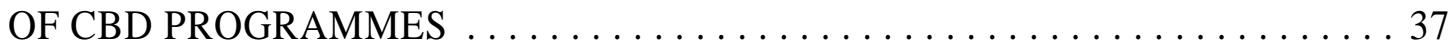

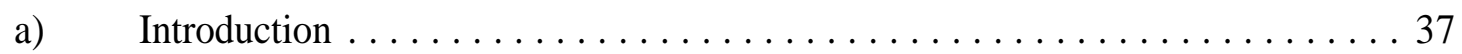

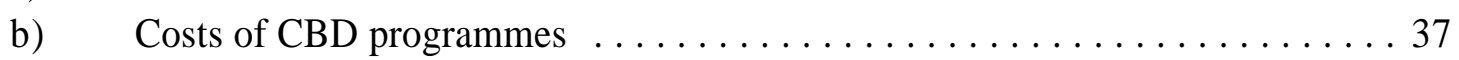

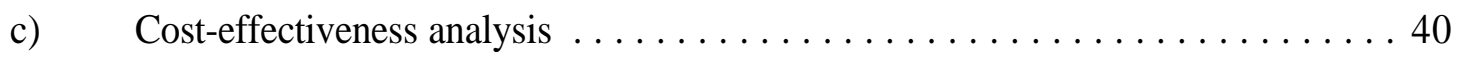

V: QUALITY OF CARE PROVIDED

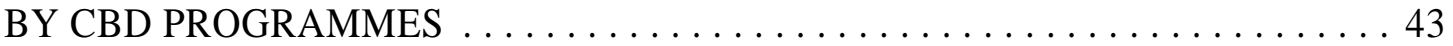

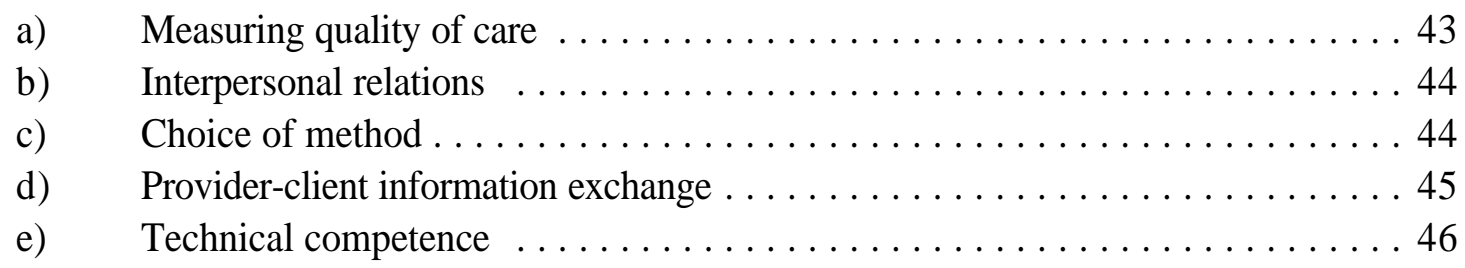




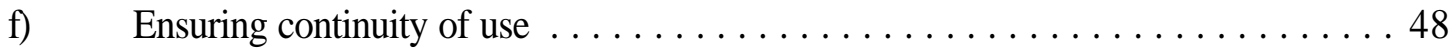

g) Appropriateness and acceptability of services $\ldots \ldots \ldots \ldots \ldots \ldots \ldots$

VI: CONCLUSIONS AND RECOMMENDATIONS

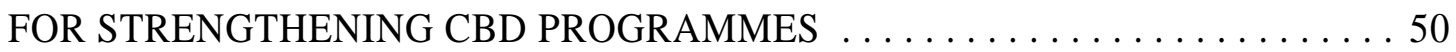

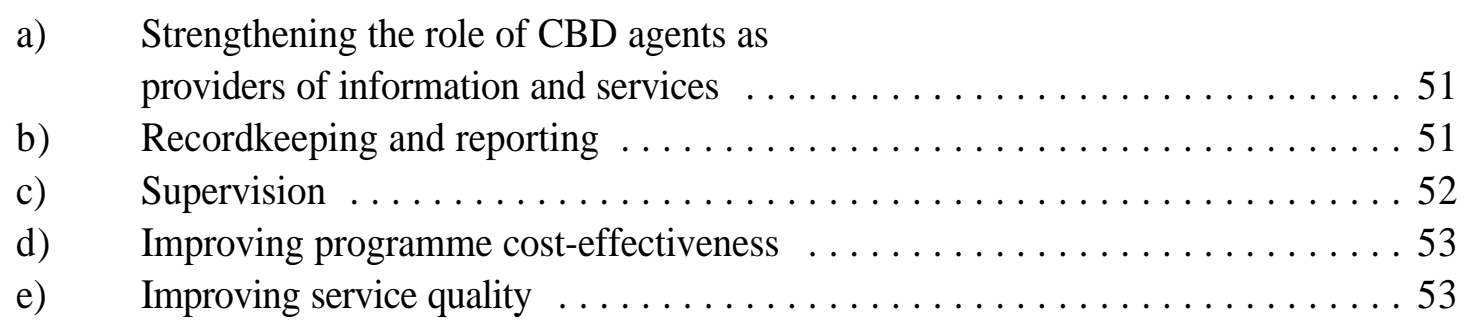

VII: DISSEMINATION AND UTILIZATION

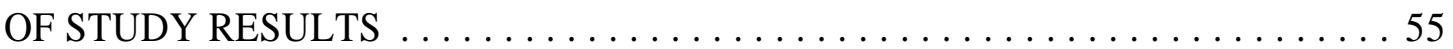

APPENDIX I: Descriptions of CBD Programmes $\ldots \ldots \ldots \ldots \ldots \ldots \ldots \ldots \ldots \ldots \ldots \ldots \ldots \ldots \ldots$

a) Family Planning Association of Kenya (FPAK) Programme . . . . . . 57

b) Maendeleo Ya Wanawake Organization (MYWO) Programme . . . . . 57

c) Christian Health Association of Kenya (CHAK) Programme . . . . . . . 58

d) Ministry of Health / GTZ (MOH/GTZ) Programme . . . . . . . . . . 58

e) Family Life Promotion and Services (FLPS) Project . . . . . . . . . . . . 59

f) Nairobi City Council (NCC) Projects . . . . . . . . . . . . . . . . . 59

APPENDIX II: Calculating programme costs and sensitivity analysis $\ldots \ldots \ldots \ldots \ldots \ldots$

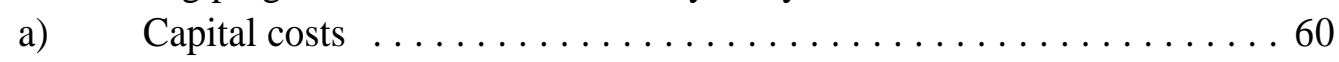

b) Recurrent costs ......................6 61

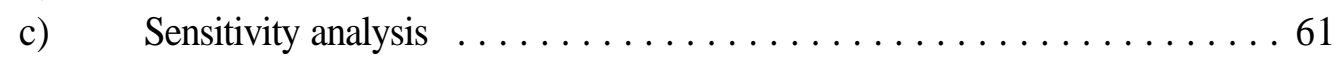




\section{EXECUTIVE SUMMARY}

Kenya has a long history of using communitybased distribution (CBD) as an integral part of its family planning programme. The purpose of this study was to assess the role of CBD programmes in terms of providing information and services, to learn more about the determinants of programme effectiveness, and to attempt to compare the programmes cost-effectiveness. The fieldwork was undertaken in mid-1995 when data were collected from seven of the major CBD programmes in Kenya. Four rural and three urban programmes were included, as were programmes that remunerated their agents and those that did not, and programmes that had full-time agents and those that had part-time agents. Data on the programmes themselves were collected from records and from interviews with managers and staff, as well as from a sample of CBD agents. Data were also collected from representative samples of the population living in the agents', catchment areas. The key findings and programmatic recommendations are given below.

\section{1) The role of CBD agents in providing family planning information and services}

C One-half of the women and men interviewed in the catchment areas said that they knew of an agent; these proportions were higher for the rural programmes.

C Almost 30 percent of all women and men reported having seen the CBD agent talking at a public meeting, and CBD agents have met directly with approximately one-quarter of the women and one fifth of the men in their catchment areas.

C Almost one-half of the women meeting with an agent reported receiving or being referred for the pill, and one-quarter of the men reported being given condoms.

C CBD agents do not play a major role as a first source of family planning information but they do play a role as the main or additional sources of information.

C Among women who get their method from a CBD agent, more than half cite the agent as their main source of information. Among men who know of a CBD agent, the agent is by far the main source of information. 
C When all female users of supply methods are considered, the proportion obtaining their method from a CBD agent is 40 percent, and amongst pill users 44 percent. For those women who know of a CBD agent in their community, the proportion of pill users who get their method from a CBD agent is substantially higher, at 57 percent.

C The CBD agent is the main source of supply of condoms for men who know of a CBD agent in their community.

C Women who use a supply method and have access to both a CBD agent and a clinic are somewhat more likely to get their method from a CBD agent than a clinic. Women's choice of source is not associated with their age, maritalstatus, parity or religion. Unmarried, younger women are equally likely to be served by a CBD agent as a clinic.

C The vast majority ofrespondents felt that CBD agents should discuss family planning with youth and with those who are not married. The youth remain an under-served group for CBD programmes, in terms of both information on sexuality and contraception and provision of services. The agents' attitudes towards providing contraceptives is clearly gender-biased, however. The vast majority of respondents favored the idea of CBD agents providing STD/HIV information and counseling.

\section{Recommendations for increasing the role of $C B D$ agents in the community:}

1) Greater publicity about the presence of a CBD agent and their work in a community would increase the number of people who use them for information and services.

2) Agents located in areas with low contraceptive prevalence rates should be given extra attention and support by the programme as it has proven harder for them to provide services in such environments.

3) CBD agents should be trained more thoroughly in other reproductive health issues and encouraged to act as sources of information for other community members, especially the youth.

4) National and programme policy guidelines should spell out clearly the need to meet the reproductive health needs of youth and especially of individuals and couples looking to delay their first birth.

5) CBD programmes should train their agents in the implications of adolescents' sexual behavior and in the gender factors surrounding contraceptive use and sexual health.

6) CBD programmes need more males as agents, and also encourage their agents to meet with males directly, either individually or through their wives. They should also be prepared to talk more about vasectomy to couples looking to limit their family size. 


\section{2) Programme performance}

C Agents in the urban-based programmes are meeting more clients than agents in the rural programmes.

C CBD agents appear to be serving more revisits than new clients.

C Agents located in areas with higher contraceptive prevalence rates performed better than agents from the same programme in sites with a lower CPR.

C An agent's age, educationallevel, maritalstatus and religion make very little difference to their productivity.

C The ruralprogrammes provide most of their CYP through the pill, but in the urban programmes, the distribution between methods is either more equal or heavily in favor of the condom.

C The agent-supplied methods generate higher levels of CYP than referrals.

C Although the largest number of referrals by CBD agents are for clients wanting to use the injectable, those clients referred for female sterilization generate the highest levels of CYP.

C The greatest numbers of clients met, referrals, and CYP were generated by agents in the urban-based NCCFP and the rural-based FPAK programmes.

C The average CYP generated per client met for agent-supplied methods is between 0.12 and 0.2 ; thus, it takes 5 - 8 meetings with clients to generate one CYP.

C Methods of making client referrals (using a referralcard, accompanying the client to the clinic, or verbal referral) vary across agents with no pattern being associated with a particular program. Most staff from clinics with an established CBD referral system reported that there had been no problems; indeed, almost one-half of the staff reported that they also refer their clients to the CBD agents. However, almost one-third of the agents said that some of their clients had complained to them about bad treatment at the clinic.

\section{3) Recording and reporting}

C Whether the number of family planning acceptors and CYP are the most appropriate indicators for a CBD programme is an issue for debate.

C A substantial amount of the CBD agents time is spent discussing family planning generally, as well as a myriad of other reproductive and sexual health issues that are not recorded. 
C Not only do the existing recordkeeping and reporting systems require some strengthening to produce more valid data, the types of activities reported and the indicators used to assess CBD programmes need to be reconsidered.

C Although most programmes require their agents to record their non-family planning activities, these data were not routinely reported to the programme headquarters. Reporting effective referrals is clearly difficult and inconsistent.

\section{Recommendations for strengthening recordkeeping and reporting}

1) Recordkeeping systems should be reviewed for the relevance of the data collected and a uniform recording and reporting system are developed and adapted. Particular attention should be paid to recording and reporting the many non-family planning activities which CBD agents undertake, including general information-giving on family planning and other reproductive health issues. This is particularly important in areas with low contraceptive prevalence and/or poor utilization of other reproductive health services.

2) For family planning services, agreement should be reached on a uniform definition of a new user. It is suggested that it be a new "acceptor," and a category of "continuing" user be used for those who are new to the CBD agent.

3) A series of performance andmonitoring indicators that adequately reflect both the family planning and non-family planning activities undertaken by CBD agents should be considered and developed as a standard set to ensure that programmes can be fully evaluated and compared.

4) Each programme should review its reporting procedures, so that summary records kept at all levels are identical.

5) Formulate national guidelines to systematize the referral of clients by CBD agents to clinics and to record and report on these activities.

6) Include referral clients (for both FP and non-FP services) and CYP generated by referrals as performance indicators.

\section{4) Supervision}

C Most CBD agents reported receiving three supervisory visits in the previous three months, that is, receiving the suggested level of supervision. Nearly one-half of the agents were not happy with the current frequency of supervision. 
C The four programmes with the highest average outputs per CBD agent all have supervisory systems that require the supervisor to have individualand group supervisory contacts with CBD agents on a monthly basis.

C CBD agents who are supervised more frequently tend to meet with more clients.

Recommendations for strengthening supervision
1) have full-time field-based staff as the immediate supervisor for CBD agents;
ensure and maintain a monthly supervisory schedule with fixed dates for individual
meetings with agents;
develop and implement a supervisory checklist to guide supervisors;
encourage notes to be kept of the supervisory visit by both the supervisor and the agent
for monitoring future activities.

\section{6) Costs and cost-effectiveness}

C The relationship between level of remuneration and performance is not at all straightforward, although there was a weak but significant relationship between level of remuneration and the number of client visits made and amount of CYP provided. However, higher pay does not automatically lead to higher outputs. Agent remuneration may override the influence of the demand environment. Remuneration does appear to influence agent satisfaction, but the nonmonetary benefits gained from being an agent may also influence performance.

C Remuneration of CBD agents, through allowances and salaries, takes between 11 and 19 percent of the budget for those programmes which give financial remuneration.

C Costs incurred for CBD training are a small proportion of the total program costs.

C Transportation costs are a substantial proportion of the annual costs for the MYWO and CHAK programmes.

C The proportion of costs spent in the field were far greater than those incurred at headquarters.

C Most programmes were able to limit the costs of meeting clients to Kshs 70 - 106 (i.e. \$1.3 \$1.9) per client met, and of providing one CYP to Kshs 625 - 742 (\$11.2 - \$13.5).

C Rural and urban CBD programmes can achieve similar levels of cost-effectiveness. For those programmes which appear to be less cost-effective the reason cannot be attributed to where they operate. 


\section{Recommendations for improving cost-effectiveness}

1) The two programmes which do not currently remunerate their agents (MOH/GTZ and NCCS) should consider introducing a moderate level of remuneration as this may increase agent satisfaction and reduce the likelihood of agents dropping out early.

2) The two programmes with the highest cost-effectiveness ratios (MYWO and FLPS) should look for ways to increase the volume of service provided within their existing structures.

\section{7) Quality of care}

C Most agents try to find out, at least broadly, their clients' reproductive intentions.

C While the vast majority of the CBD agents who were interviewed did have supplies of pills and condoms available, very few had any spermicides.

C Almost 80 percent of the CBD clients interviewed said that the agent discussed methods other than the one they chose, and told them that they could change the method if they wanted to, and 90 percent said that they received their preferred method.

C Three-quarters of the clients reported that the agent asked them about their medical history, indicating that some form of screening for inappropriate methods is also taking place. But almost one-quarter of the agents did not have a pill screening checklist with them on the day of the interview.

C Agents put most emphasis on telling clients how to use the pill and less on establishing a client's needs or informing her of the side effects and their management.

C Although STD/HIV prevention and management are part of the national CBD training curriculum, 15 percent of the agents said that they had not received any formal training on these topics. Forty percent of agents felt that their training was inadequate for providing family planning, and of those who had been trained in STD/HIV, one-half felt it was not adequate.

C Significant differences exist between the programmes in terms of their agents' knowledge of pill and condom use, primary and secondary contraindications and side effects of the pill. Full knowledge of how to use the condom properly was poor. 


\section{Recommendations for improving Quality of Care}

1) Spermicide supplies should be better maintained, and agents should continuously have supplies of both combined and progestin-only pills.

2) Basic and refresher training on family planning should reinforce the need to inform clients about possible side effects and their management.

3) Supervisors must ensure that agents keep the pill screening checklist with them at all times and use it with every new client.

4) The national training curriculum and the training departments of the CBD programmes must strengthen their coverage of other health issues, especially the signs and symptoms of RTIs/STIs, correct breastfeeding and management of diarrhoea and malaria. The importance of discussing family planning and other reproductive health issues in the context of human sexuality should be emphasized during training and agents given suggestions and support in how best to do this. 


\section{BACKGROUND AND METHODOLOGY}

\section{a) CBD programmes in Kenya}

In an attempt to increase the acceptability and accessibility ofmodern contraceptives, Kenya adopted the Community-Based Distribution (CBD) strategy in the early 1980's. This approach had been tried previously in Asia and Latin America and found to be feasible, safe, effective and acceptable to communities (Phillips \& Green, 1993). Kenya has since become one of the leading countries in Africa in developing and implementing CBD programmes as part of the national family planning programme.

CBD is a non-clinical strategy through which community members (with or without remuneration) provide family planning services and information at convenient locations in villages, markets and at homes. It is based on the premise that making contraceptives available at convenient locations will increase their acceptability to those who would not utilize services provided in clinical settings only, and their accessibility to those who live far from clinics. It is also assumed that enlisting community members as contraceptive providers will reduce the "social distance" usually experienced between clients and medically-trained providers (Ross et al., 1987). In Kenya, the CBD programme is also expected to reduce clinics' client load by providing non-clinical methods to clients who would otherwise get these methods from the clinics.

The Family Planning Association of Kenya (FPAK) was the first organization to establish a CBD programme in 1982, and was quickly followed in 1983 by Chogoria Hospital (a church-based hospital) and the womens' organization Maendeleo Ya Wanawake Organization (MYWO). Since then, a number of different organizations, including non-governmental organizations (NGOs), churchbased organizations, the Ministry of Health $(\mathrm{MOH})$ and some municipal authorities, have developed their own CBD programmes with technical and financial support from donor agencies. All CBD activities are coordinated by the National Council for Population and Development (NCPD). An inventory of CBD programmes undertaken in 1991 established that there were about 25 agencies with a total of more than 10,000 CBD agents providing CBD services in seven of the eight provinces, 37 of the 41 districts, and more than 35 percent of all the sub-locations in the country (Barasa \& Kanani, 1991). Although the proportion of the total population covered by CBD programmes is not known, the 1993 Kenya Demographic and Health Survey (KDHS) showed that 48 percent of its respondents live in areas served by CBD agents (NCPD et al., 1994).

The Kenyan setting for CBD programmes is characterized, therefore, by a variety of different approaches to CBD service delivery, and has rightly been described as "a laboratory of CBD diversity" (Phillips and Green, 1993:31). In some form or other, virtually every approach to CBD that has been tried in different regions of the world is represented in Kenya. The programmes vary in the strategies they apply, their geographic coverage, the number of agents involved, the catchment areas served by their CBD agents, the links with clinics, their requirements for a medicalexamination for new pill clients, the range of services provided by the agents, and in the status, remuneration, recruitment and supervision of the agents. 
Moreover, until 1990, the CBD agencies operated without any policy guidelines. In August 1990, the NCPD and the MOH's Division of Family Health(DFH), with technicaland financialsupport from the Population Council's Africa Operations Research and Technical Assistance Project, held a workshop to discuss key design and implementation issues, with the aim of coming up with policy guidelines for CBD programmes. Guidelines relating to medical issues and a screening checklist, logistics and health information systems, job remuneration and support for CBD agents, geographical coverage, and the selection, training and supervision of CBD agents, were drawn up during this workshop, but were not formally endorsed as Government policy. A second workshop was held in 1994 (with financial and technical support from Pathfinder International) to explore these policy issues further, but to date no formal policy guidelines have yet been developed. Consequently, apart from use of the NationalCBD Training Curriculum which has been adopted by all CBD agencies, there is much room for flexibility in the way each organization interprets the guidelines.

\section{b) Rationale for the study}

The widespread variations in approaches to implementing CBD programmes in Kenya, while undoubtedly a strength of the family planning programme overall, are somewhat confusing to policy makers, programme planners and donors. A need has been expressed, primarily by USAID (the principal donor supporting CBD programmes in Kenya) but also by others, for empirical evidence concerning the effectiveness, cost-effectiveness and performance of the different approaches whichcan be used to guide programme planning and future resource allocations. This study was developed, therefore, to address a number of important issues.

i) The impact of the CBD strategy on reaching and serving family planning clients. A review of key research studies on CBD programmes in Kenya by Mundy and Askew (1994) revealed conflicting findings concerning the impactofCBD programmes on the knowledge and use of contraception, and the factors accounting for the choice of sources of information and contraceptives. For example, the 1993 KDHS indicated that only $3.9 \%$ of all women interviewed identified CBD agents as their main source of family planning information and only $2.5 \%$ mentioned a CBD agent as their current source of supply for modern contraceptives (NCPD et al., 1994). These low figures have been widely referred to and have led to much debate on the effectiveness of the CBD approach. Unfortunately, the fact that this figure refers to a nationally-drawn sample, and so includes many women who do not have access to a CBD agent (because CBD programmes are not nationwide in coverage), is often overlooked ${ }^{1}$.

Another study, undertaken on behalf of MYWO, interviewed the population in all the catchment areas served by the MYWO programme. This study revealed that anywhere from one percent to 46 percent of current users in a Division covered by the MYWO programme were being served by a CBD agent (MYWO, 1995).

ii) Organizational determinants of programme effectiveness. The diversity in overall approach and organization of CBD programmes raises questions about what makes a

1 A reanalysis of the KDHS data to look at only those women who actually know of a CBD agent revealed that the proportion citing the agent as their current source of method was 7.5 percent. 
programme more or less effective. Are there, for example, relationships between programme performance and:

! the interest in and existing use of family planning where the agent works?

! the employment status and/or the remuneration provided to a CBD agent?

! the level of supervision?

! the sex of the CBD agent?

! the relationship between agents and clinics in the same geographical area?

! the personal characteristics of the agents?

iii) Cost-effectiveness of different programmes. The cost of different CBD models is of central importance to donors and policy makers. The cost data currently available for programmes in Kenya are at an aggregate level only and give no indication of the relative expenditures on different components of a programme. These data are thus limited in their usefulness in guiding funding allocations and identifying areas in which programmes could use resources more efficiently. Moreover, knowing the cost-effectiveness of the different programme approaches is extremely helpful in planning future resource allocation strategies, yet no cost-effectiveness analysis has ever been undertaken of CBD programmes in Kenya. This study attempts to calculate cost-effectiveness ratios for different programmes, although data limitations for both the cost and effectiveness measures require that the results are interpreted with some caution.

iv) Impact of CBD work on female agents' lives. A multi-country study of female field workers undertaken by CEDPA (Kak \& Narasimhan, 1992) found that family planning field work provides an opportunity for women's self-enhancement at both the family and the community levels. This study follows the broad analytical framework used in the CEDPA study but includes both private and public sector organizations with different CBD remuneration strategies.

v) CBD agents as reproductive health service providers. The actual and potential role of CBD agents in undertaking non-family planning activities is ofincreasing interest with the current emphasis on providing family planning services in a broader reproductive health context; for example, most CBD programmes in Kenya are already providing some limited STD/HIV education and management services. This study reviews which elements of reproductive health care, other than family planning services, are currently being undertaken and which elements could be effectively added to CBD agents' current functions.

The results of this study are expected to be useful not only to CBD programme managers and donors in Kenya, but also to other countries in the African region interested in developing or improving their CBD programmes. 
In addition, it is hoped that a better understanding of the performance, impact and possible future directions of the different CBD programmes will provide answers to questions such as:

! how best to allocate resources for CBD programmes so that they are used cost-effectively;

! what guidelines should be given to CBD managers for planning the structure and organization of their programmes in the future;

! what goals should be set and indicators used for evaluating CBD programmes?

\section{c) Study design}

This study compared seven of the major CBD programmes in Kenya, each of which represents a different model for providing family planning information and services at the community lever. The study was designed to incorporate the variations in activities, organization, outputs and scale between different CBD models. Among the more than 20 different CBD programmes (and organizational models) currently operating in Kenya, some grouping into broad types is possible. Drawing on the classification proposed by Mundy and Askew (1994) one program within each of the following categories was selected for the study:

1) UrbanClinic Outreachmodels - CBD agents (either full-time salaried or part-time volunteer) working in the communities surrounding an urban clinic, and based at and fully supported by the clinic.

a) Part-time CBD agents, given an allowance and supervised/attached to their organization's clinic - Family Life Promotionand Services (FLPS) Project (NGO sector)

b) Part-time CBD agents given non-monetary incentives and supervised/attached to their organization's clinic - Nairobi City Council Slum (NCCS) Project (public sector)

c) Full-time CBD agents, given a salary and supervised/attached to their organization's clinic - Nairobi City Council Family Planning (NCCFP) Project (public sector)

2 Kenya also has examples of two other types of non-clinical family planning service delivery models, a social marketing programme, implemented by Population Services International (PSI), and an employment-based programme, implemented by Family Planning Private Sector (FPPS) Project of John Snow Incorporated (JSI). The study did not include examples of these programmes as their characteristics are too different from the conventional CBD models being examined. 
2) Rural Village Depot/Home Visit models - part-time CBD agents based in their own rural community, supervised either by staff from the programme's own clinic or by staff from the organization itself. CBD agents may either visit clients at their home or clients come to their homes or contraceptive "depots".

a) Part-time CBD agents, given non-monetary incentives and supervised/attached to their organization's clinic - MOH/GTZ programme (public sector)

b) Part-timeCBD agents, given an allowance, supervised by programmestaff and normally attached to the organization's clinic - Family Planning Association of Kenya (FPAK) programme (NGO sector)

c) Part-time CBD agents, given an allowance, supervised by programme staff and not attached to a clinic - Maendeleo Ya Wanawake Organization (MYWO) programme (NGO sector)

d) Part-time CBD agents, given an allowance, supervised/attached to the organization's clinic, and working within a church-based organization - Christian Health Association of Kenya (CHAK) (church sector).

More detailed descriptions of each programme are given in Appendix One; a summary is presented in the table below.

Table I.1: Summary characteristics of CBD programmes

\begin{tabular}{||c|c|c|c|c|c|c|c||}
\hline Agency & Location & Sector & $\begin{array}{c}\text { Year } \\
\text { started }\end{array}$ & $\begin{array}{c}\text { \# CBDs } \\
\text { in 1994 }\end{array}$ & $\begin{array}{c}\text { CBD } \\
\text { status }\end{array}$ & $\begin{array}{c}\text { Direct } \\
\text { clinic link }\end{array}$ & Coverage \\
\hline MOH/GTZ & Rural & public & 1991 & 4,158 & $\begin{array}{c}\text { Volunteer/ } \\
\text { incentives }\end{array}$ & Yes & $\begin{array}{c}2 \text { provinces } \\
6 \text { districts } \\
538 \text { sub-loc }\end{array}$ \\
\hline MYWO & Rural & NGO & 1983 & 1,239 & $\begin{array}{c}\text { Part-time/ } \\
\text { allowance }\end{array}$ & No & $\begin{array}{c}5 \text { provinces } \\
12 \text { districts } \\
32 \text { divisions }\end{array}$ \\
\hline FPAK & Rural & NGO & 1982 & 734 & $\begin{array}{c}\text { Part-time/ } \\
\text { allowance }\end{array}$ & Yes/No & $\begin{array}{c}7 \text { provinces } \\
18 \text { districts } \\
40 \text { divisions }\end{array}$ \\
\hline CHAK & Rural & Church & 1989 & 525 & $\begin{array}{c}\text { Part-time/ } \\
\text { allowances }\end{array}$ & Yes & $\begin{array}{c}5 \text { provinces } \\
9 \text { districts } \\
20 \text { divisions }\end{array}$ \\
\hline FCCS & Urban & public & 1989 & 257 & $\begin{array}{c}\text { Volunteer/ } \\
\text { incentives }\end{array}$ & Yes & $\begin{array}{c}\text { Full-time/ } \\
7 \text { urban slums }\end{array}$ \\
\hline NCCFP & Urban & public & 1987 & 44 & Yes & Yart-time/ \\
\hline allowance
\end{tabular}


The rural programmes cover large geographical areas having high, medium and low contraceptive prevalence rates and population densities. Their agents tend to function independently although they have links with their organization, either directly or through the clinics.

The urban programmes are smaller in size and coverage and serve more densely populated communities in areas of relatively high contraceptive prevalence. The agents are directly linked with the organizations' clinics.

With the exception of the MOH programme (which is supported by GTZ) and the NCCS project (supported by UNFPA), almost all CBD programmes in Kenya are supported by USAID, either directly (e.g. the FPAK and CHAK programmes) or through two Collaborating Agencies, Pathfinder International (the MYWO and NCCFP programmes) and CEDPA (the FLPS project and the MYWO programme).

\section{d) Sampling}

\section{i) Programme sites}

Sites representative of each programme were selected using the following four criteria:

1) Prevalence of contraceptive use in programme catchment area. To control for the possibility that CBD programme performance may vary according to the existing use of and demand for family planning, for each rural-based programme two sites were selected, one with high and one with low contraceptive prevalence rates $(\mathrm{CPR})^{3}$; for the urban programmes, prevalence was assumed to be uniform throughout. Two sites were selected for each programme so that one was located in a high prevalence district and one in a low prevalence district.

2) CBD programme operating in isolation. In many parts of Kenya more than one CBD programme operates in the same geographic area. To be able to assess the impact of each programme individually, each study site was selected on the basis that it was the only CBD programme operating within that division ${ }^{4}$.

3) Programme operating for at least three years. To allow a programme sufficient time to become established and have an impact every programme should have been operating in the selected site for a minimum of three years.

3 Using the 1993 KDHS national CPR of 27 percent for modern contraceptives, the districts in which the programmes operate were categorized as either high or low prevalence according to whether they came within one quartile on either side of 27 percent.

The MOH/GTZ programme operates only in Western and Nyanza provinces, and almost every division in both provinces has more than one CBD programme. Consequently, it was possible only to select both $\mathrm{MOH} / \mathrm{GTZ}$ sites in Nyanza province, and thus the MOH/GTZ programme in Western Province is not represented. 
4) Similar population characteristics within urban sites. In Nairobithere are wide variations in the population's culturaland socioeconomic characteristics even within a division and so only one division was selected for each of the urban programmes.

Following these criteria, a multistage sampling design was used to select the study sites. Firstly, districts were purposively selected according to contraceptive prevalence rate, location of only one CBD programme, and the programmes operating for at least three years. Secondly, within each district one division was randomly selected from amongst those in which the CBD programme operates, and then up to ten sub-locations/villages within each division were selected randomly. Using these criteria, the following sites were identified.

Table I.2: Study sites

\begin{tabular}{|c|c|c|c|c|c|c|c|}
\hline \multirow[t]{2}{*}{ Programme } & \multirow[t]{2}{*}{ District } & \multirow[t]{2}{*}{ Division } & \multirow[t]{2}{*}{$\mathrm{CPR}^{1}$} & \multicolumn{2}{|c|}{$\begin{array}{c}\text { No. of } \\
\text { Sublocations } \\
\end{array}$} & \multirow{2}{*}{$\begin{array}{l}\text { No. of } \\
\text { CBD } \\
\text { agents } \\
\text { at site }\end{array}$} & \multirow{2}{*}{$\begin{array}{c}\text { Eligible } \\
\text { Pop. }{ }^{2} \text { per } \\
\text { CBD } \\
\text { agent }\end{array}$} \\
\hline & & & & $\begin{array}{l}\text { with } \\
\text { CBD }\end{array}$ & $\begin{array}{c}\text { without } \\
\text { CBD }\end{array}$ & & \\
\hline \multirow[t]{2}{*}{ FPAK } & Nyeri & Tetu & 59.3 & 28 & 2 & 37 & 850 \\
\hline & Kilifi & Kaloleni & 17.9 & 30 & 6 & 41 & 1,772 \\
\hline \multirow[t]{2}{*}{ MYWO } & Murang'a & Gatanga & 56.2 & 7 & 9 & 47 & 670 \\
\hline & Nandi & Aldai & 36.6 & 17 & 4 & 39 & 757 \\
\hline \multirow[t]{2}{*}{ CHAK } & Meru / Nyambene & Igembe & 41.4 & 10 & 2 & 50 & 994 \\
\hline & Kericho & Buret & 27.6 & $\mathrm{~N} / \mathrm{A}^{3}$ & $\mathrm{~N} / \mathrm{A}^{3}$ & 34 & 1,545 \\
\hline \multirow[t]{2}{*}{ GTZ } & Kisii / Nyamira & Ekerenyo & 27.0 & 8 & 2 & 103 & 351 \\
\hline & S.Nyanza / Homa Bay & Kasipul & 18.2 & $\mathrm{~N} / \mathrm{A}^{3}$ & $\mathrm{~N} / \mathrm{A}^{3}$ & 157 & 315 \\
\hline $\mathrm{NCC}^{4}$ & Nairobi & Kasarani & 38.8 & 4 & 5 & 129 & 1,370 \\
\hline FLPS & Nairobi & Makadara & 40.2 & 4 & 6 & 20 & 4,751 \\
\hline
\end{tabular}

Notes:

1. The districts were selected originally according to the CPR recorded in the 1993 KDHS, but the CPR values presented are those derived from the catchment area surveys conducted during this study as they are more accurate.

2. Eligible population includes women aged, 15-49 and men aged 19-54; data from the 1989 Census.

3. Due to administrative reorganization, these data are not available.

4. The two NCC programmes operate in the same division and so it was not possible to identify separate catchment areas for each programme. 


\section{ii) Population served by CBD programmes}

At every study site a questionnaire survey was undertaken to collect data from a sample of women aged 15-49 years and of men aged 19-54 years; these are considered to be the eligible population that is within the reproductive age range. The resulting sample size ${ }^{5}$ for the total population was then divided into two thirds women and one-third men in an effort to obtain a representation from both sexes.

A sample of households was drawn from up to ten of the sub-locations in the division, with the condition that every location be represented; the sample for each sublocation was proportional to the size of its eligible population. The households were identified through drawing a systematic random sample from a newly-created population listing $^{6}$. All eligible persons in each sampled household were then listed and one person randomly selected for the interview so that in total two-thirds of respondents were female and one-third male. A total of 2,105 females and 1,027 males were interviewed.

Their characteristics are described in Table I.3 and are fairly similar to that drawn by the $1993 \quad$ K D H S ; th e s a m ple is felt to be representative of the larger population. Those in the urban areas tended to be slightly younger, better educated and more likely to be non-married people and, for some reason Catholic, than the $\mathrm{r}$ u r a $1 \quad \mathrm{p}$ o p u la $\mathrm{t}$ i o n. Amongst the 39 percent of women who were currently using family planning,

5 The standard formula for calculating minimum samples for a population survey using random sampling was used, with the district-level CPR as the variable of interest and a 95\% confidence level.

The national sampling framework constructed by the Central Bureau of Statistics (CBS) for the 1989 national census could not be used because it does not necessarily cover the CBD catchment areas. Therefore, new clusters covering the sample sub-locations were created through listing all households in the selected area. Where a CBS cluster existed, it was updated. 
most were using the pill (26 percent), injectable (22 percent) or rhythm and/or withdrawal (18 percent), although 13 percent were sterilized and 9 percent were using an IUD. Four percent were using the condom.

\section{iii) CBD agents}

For every study site a sample of approximately $20 \mathrm{CBD}$ agents was drawn at random from the total number currently active. A total of 199 CBD agents, comprising 158 females and 41 males, were interviewed.

\section{iv) Clinic staff}

For every study site, all clinics to which the CBD agents are attached/supervised or to which they refer their clients were included. The staff selected for an interview had to have worked at the $\mathrm{MCH} / \mathrm{FP}$ unit of the clinic for at least one year. Where the staff person in charge of the MCH/FP unit at the clinic met this criterion, she or he was interviewed. A total of 62 staffs, comprising 48 females and 14 males, and representing 62 clinics were interviewed. Most (46) were Kenya Enrolled Community Nurses / Nurse Midwifes, 9 were the Sisters in-charge, two were Kenya Registered Community Health Nurses, four were Nutritionists, and four were Clinic Assistants.

Table I.4: Sample sizes for catchment area survey

\begin{tabular}{|c|c|c|c|c|c|c|}
\hline \multirow[t]{2}{*}{ Programme } & \multicolumn{3}{|c|}{ Population } & \multicolumn{2}{|c|}{ CBD agents } & \multirow{2}{*}{$\begin{array}{l}\text { Clinic } \\
\text { Staff }\end{array}$} \\
\hline & Male & Female & Total & male & female & \\
\hline FPAK, high CPR & 121 & 253 & 374 & 0 & 20 & 6 \\
\hline FPAK, low CPR & 68 & 134 & 202 & 4 & 16 & 6 \\
\hline MYWO, high CPR & 121 & 242 & 363 & 0 & 20 & 9 \\
\hline MYWO, low CPR & 88 & 175 & 263 & 1 & 19 & 7 \\
\hline CHAK, high CPR & 118 & 263 & 381 & 13 & 7 & 4 \\
\hline CHAK, low CPR & 90 & 181 & 271 & 2 & 18 & 7 \\
\hline $\mathrm{MOH}$, high CPR & 124 & 241 & 365 & 7 & 13 & 6 \\
\hline $\mathrm{MOH}$, low CPR & 68 & 132 & 200 & 3 & 17 & 3 \\
\hline $\mathrm{NCC}$ & 115 & 245 & 360 & 9 & 11 & 7 \\
\hline FLPS & 114 & 239 & 353 & 2 & 17 & 7 \\
\hline Total & 1027 & 2105 & 3132 & 41 & 158 & 62 \\
\hline
\end{tabular}




\section{e) Data collection, processing and analysis}

Several data collection methods were used including:

! a review of programme documents,

! abstraction of programme service statistics and financial records,

! in-depth interviews with programme managers and staff,

! structured interviews with CBD agents;

! inventory of CBD agents' equipment and supplies;

! structured interviews with clinic staff;

! structured interviews with men and women of reproductive age.

Data on programme coverage, structure and operating procedures, outputs, and costs were collected through a review of documents and service statistics, as well as through in-depth interviews with key staff at the national and division levels. To assess the contribution of CBD programmes to knowledge, attitudes and use of family planning and reproductive health and other public health information and services, data were collected through interviews with the respondents in the site catchment areas.

Data on the quality of services provided by CBD agents, the agents' relationship with clinics, factors related to the agents' performance, and the agents' view on the impact of the CBD work on their personal lives were collected through interviews with the sample ofCBD agents at each site. Data on impact of CBD work on agent's personal life and the quality of services provided by CBD agents were also collected through the interviews with men and women, and through an inventory of the agent's equipment and supplies. The agents' relationship with the clinics was assessed through openended interviews with clinic staff.

Quantitative data were entered and edited using the Epi Info programme and statisticalanalyses were undertaken using the SPSS programme. The interview guides for CBD programme managers and for clinic staff and several questions in the CBD agent questionnaire contained open-ended questions, the answers to which were categorized into a limited number of responses to enable the results to be analyzed quantitatively. The cost data were processed and analyzed using the Lotus 1-2-3 programme. Descriptive and bivariate statistics have been used to present results according to the major objectives of the study. 


\section{ROLE OF CBD AGENTS IN PROVIDING FAMILY PLANNING INFORMATION AND SERVICES}

\section{a) Awareness among community members of CBD Agents}

For a CBD agent to have any impact, community members must first be aware of their presence. All respondents were asked whether they knew of a person in their community who provides information and services on family planning. Overall, 50 percent of women and 47 percent of men interviewedsaid that they knew of such a person. These proportions varied tremendously by CBD programme, however, as illustrated by Figure II.1.

These differences are probably because the CHAK, FPAK and MYWO programmes are more mature than the others, and they operate in rural areas where social networks are generally more intense and communities more stable over time than in urban areas. The $\mathrm{MOH}$ programme, although serving rural communities also, only began operations in $1991^{7}$. As would be expected, the results also show that CBD agents were better known in those areas with higher contraceptive prevalence rates, a relationship that holds after controlling for type of programme.
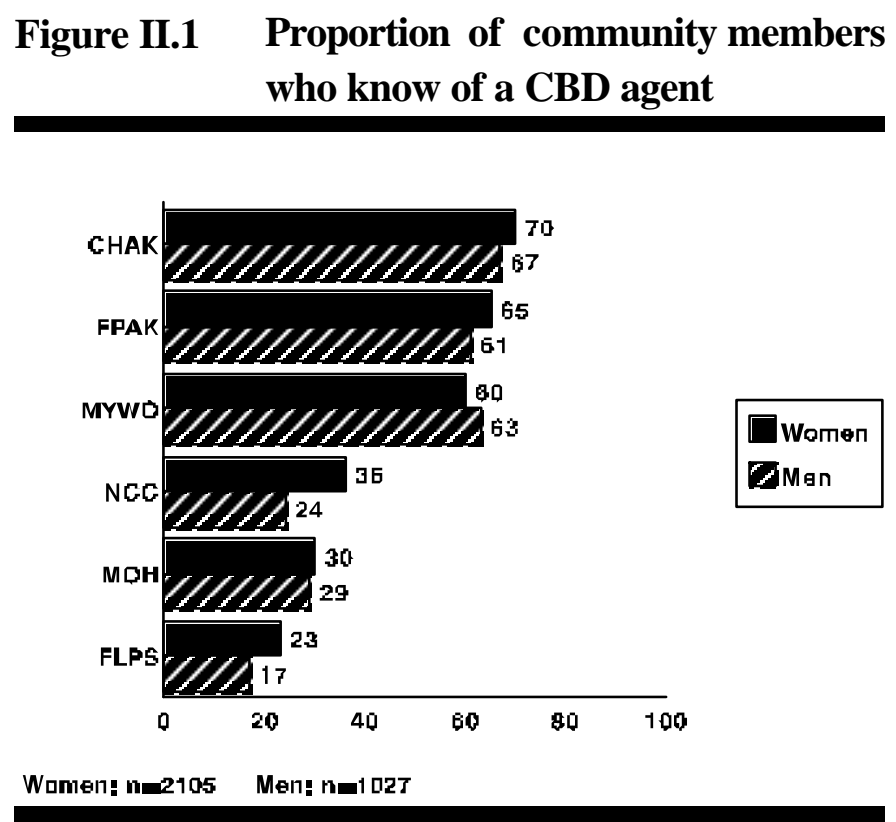

Those respondents indicating that they knew a CBD agent were then asked if they knew the person's name; this question was asked as a measure of their familiarity with the agent as opposed to simply having heard of them. Overall, 69 percent of the women and 63 percent of the men who knew of the CBD agent could give the correct name. Interestingly, this also varied by programme, with respondents more likely to know the agent's name for those programmes where the agents themselves were better known. For example, the agents were best known in the CHAK catchment areas, and almost 90 percent of both women and men in these areas who knew the agent also knew their name, whereas in the FLPS area, only 19 percent of women who knew of the FLPS agent could also correctly name her or him. community, each serving a relatively small number of clients. However, the net effect should be a large proportion of community members who know the agents and receive services from them. 


\section{b) Interactions with CBD Agents}

More importantly in terms of measuring their role, are the nature and extent of contacts between the CBD agents and community members. All women and men who had ever heard of a CBD agent were asked whether they had ever seen the agent at a public meeting and whether they had ever met the agent personally to talk about family planning or to receive information or services. To illustrate the overall level of activity of CBD agents in their communities, Figure II.2 presents these questions as a proportion of the total sample. Almost 30 percent of all womenand menreported having seen the CBD agent talking at

Figure II.2 Proportion of community members having contact with a CBD agent

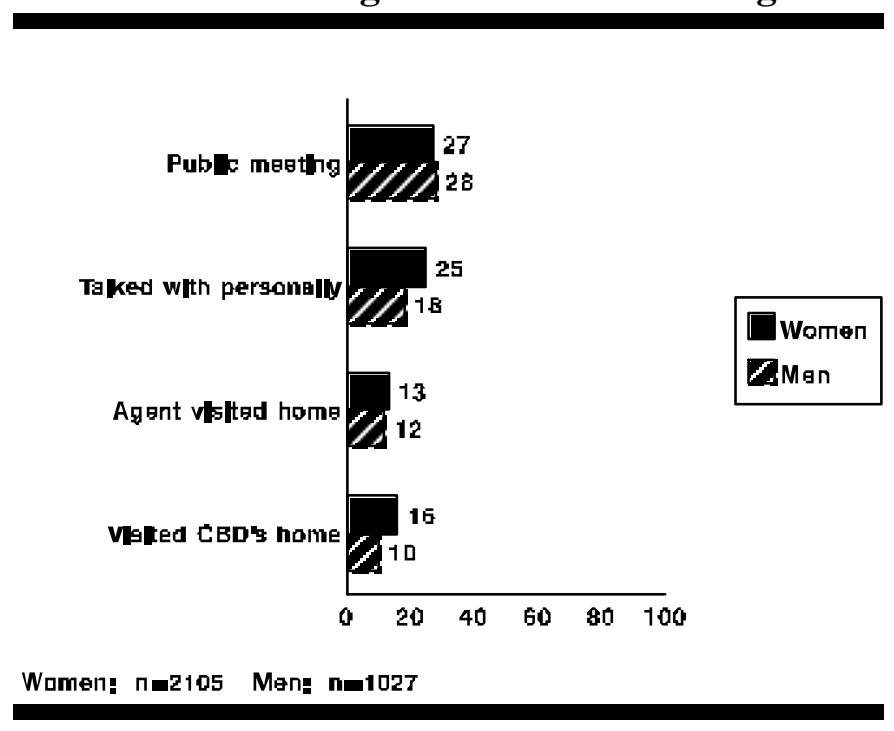
a public meeting, although there is variation across programmes: for both female and male respondents, those living in the rural CHAK and FPAK catchment areas are more likely to have seen the CBD agent talking publicly about family planning (between 38 and 52 percent), than those living in the catchment areas for the urban programmes (between 5 and 16 percent).

These data also suggest that CBD agents have directly met with approximately onequarterof the womenand one-fifth of the men in their catchment areas, although this differs by both programme and location. In the rural FPAK, CHAK and MYWO catchment areas, between up to one-third of all women have ever talked personally with an agent, compared with only between 13 and 18 percent of women in the urban areas and in the rural MOH programme area Amongst the male respondents, the CHAK programme agents are by far the most active, with 36 percent of all men having ever talked personally with the agent, while for every other programme the proportion ranges between 8 and 17 percent. These differences may again reflect the fact that the older, ruralbased programmes have been able to develop better networks between their agents and the communities.

When only those respondents who actually know of a CBD agent are considered, the proportions rise to half of the women and 37 percent of the men having ever talked with the agent. Amongst these female respondents, there is little variation across the programmes (46 - 59 percent), whereas amongst the men who know of a CBD agent, there is a clear split into two groups of programmes, those for which more than 50 percent of men have ever talked personally with the agent (MOH, CHAK, FLPS), and those for which less than one-third of the men who know of an agent have talked to the agent personally (MYWO, FPAK, NCC). Why this distinction should emerge is not immediately clear. 
Those who indicated that they had ever talked personally with the CBD agent, were asked where they had met with the agent, that is, had the agent ever visited their home, or had they ever been to the CBD agent's home or met with them elsewhere, to talk about family planning. Approximately one-quarter of both the women and men had been visited at their homes, one-third of the women and 16 percent of the men had visited the CBD agent's home, and almost one-third of the women and 42 percent of the men said that they had done both ${ }^{8}$. Thus CBD agents appear to be willing to work either from their own homes or through making home visits.

Those respondents who had ever met personally with a CBD agent were also asked which family planning methods were discussed and whether they had been given or referred for a method ${ }^{9}$. It is encouraging to note that, amongstboth womenand men, several contraceptive methods have been discussed during these meetings, and not only those methods which the agents provide themselves. While six percent of the women and eleven percent of the men said that they had talked about family planning generally without specifying any particular methods, amongst those who did mention specific methods, women reported talking about and/or receiving, on average, 3.6 different methods, and the men mentioned on average 3.5 different methods ${ }^{10}$. The majority of respondents ( 82 percent of women, 90 percent of men) felt also that the information they had received was adequate to help making a decision on family planning, although it was not possible to confirm whether this was indeed the case.

Many of these meetings included giving or referring the client for contraceptive methods. Almost one-half of the women meeting with the CBD agent reported receiving or being referredfor the pill, ranging from a high of 62 percent of interactions with CHAK agents to a low of 32 percent of interactions with $\mathrm{MOH}$ agents. Interestingly, a small proportion of men (eight percent) reported being given pills, presumably for their partners. Furthermore, a quarter of men reported being given condoms, and although the sex of the $\mathrm{CBD}$ agents serving the men is not known, this result suggests that CBD programmes with primarily female agents can and do reach men.

Twelve percent of female and 13 percent of male respondents who said that they had ever talked with the CBD agent individually also indicated that they had never been visited at home, nor had they met with the agent at their home. One interpretation of this is that they may have met the person at a public meeting or some other group situation. how many times the respondent had met with the agent. Consequently, it is not possible to distinguish whether the respondent is describing one specific meeting or is referring to actions that may have taken place over several meetings. Despite the obvious weakness of this questioning, it is felt that the results are useful in giving a general indication of the nature of the interactions. 


\section{c) Role of CBD programmes in providing family planning information and services}

Respondents were asked a series of questions about how they first heard about family planning, their main source ofinformation and, for those currently using a contraceptive method, from where they obtain their method ${ }^{11}$.

\section{I) Initial source of family planning information}

CBD agents do not play a major role as a first source of family planning information five percent for both women and men. As with the KDHS, for women the clinic is the major first source (40 percent), whereas for men it is the media (39 percent).

\section{ii) Main source of family planning information}

For both women and men, the same three sources (clinic, media and friends/relatives) are cited most frequently as the predominant sources of family planning information. CBD agents do play a role as sources of information about family planning, however, for a small proportion of men and women, that is 12 percent of women and 11 percent of men cited the CBD agent as their main source of information.

These averages hide some variation between the programme catchment areas. Amongst women, 14-15 percent of those living in the rural programme areas cite the CBD agent as their main source, whereas only two percent do so in the urban areas. For men also the average figure ofeleven percent is somewhat misleading, as there is a range between 27 percent of men living in the rural CHAK areas to 3-5 percent for those living in the urban programme areas. Those CBD agents working in rural areas clearly play a more important role as sources of information than their urban-based counterparts.

A CBD agent can only be a source of information, however, if a person knows that the agent exists, and if they have actually talked to the person. For those women and men who said that they have talked with a CBD agent, the proportions mentioning them as the main source of information rose to 35 percent amongst the women (second only to the clinic), and to 50 percent amongst the men. Indeed, amongst men who know of a CBD agent, the agent is by far the main source of information.

Among those women who actually get their method from a CBD agent (n=98), more than half of them ( 55 percent) cite the agent as theirmain source of information. However, this implies that for 45 percent of women obtaining their method from the CBD agent the agent is not their main source of information. As most of these women get most information from the clinic (26 percent),

11 Six percent of women and five percent of men said that they had never heard of family planning, and so these are excluded from the data presented in this section. 
it would appear that in these cases these CBD agents are probably being used for resupply following counseling and first provision at the clinic.

\section{iii) Source of method supply}

At the time of the survey, 39 percent of all women (42 percent of married women and 29 percent of non-married women) were currently using a family planning method and 30 percent were using a modern method. All seven programmes allow their CBD agents to provide or resupply pills ${ }^{12}$, condoms and spermicides, and encourage them to refer clients interested in other methods to the appropriate source. Moreover, all programmes expect their agents to supply unmarried and married women, and men; consequently, "all" rather than "married" women (and men) are used as the denominator in the following section.

For all current female users of Figure II.3 Source of supply for pill users modern methods, approximately 16 percent indicated that theyobtained their most recent method from a CBD agent, which rises to 22 percent amongst women who know a CBD agent. When users of supply methods only are considered (39 percent of fall users), the proportion obtaining their method from a CBD agent rises to 40 percent, and amongst pill users to 44 percent (see Figure II.3); a similar proportion was found forthe partners of the male respondents currently using the pill $^{13}$. For those women who know of a $(n=209)$

\section{CBD agent in their community, the proportion of pill users who get their method from a CBD agent is substantially higher at 57 percent.}

12 All seven programmes have similar regulations on supplying new pill clients, although these are not strictly adhered to by the agents. All agents are required to use a checklist for identifying contraindications for all new pill clients; a contraindicated client is referred to the clinic whereas those not contraindicated can be supplied with one cycle of pills and then referred to the clinic for medical check-up. If a client fails to go for medical check-up, the agents resupplies one cycle per visit up to a maximum of three cycles. Revisit clients are supplied with three cycles per visit.

13 Amongst the male respondents, 42 percent thought that their partner was currently using any method, with 27 percent using a modern method. Four men also mentioned that the CBD agents had taught their partners the rhythm method. 
Amongst the male respondents, 17 percent $(n=172)$ were currently using a condom themselves (with any partner). Because of the small numbers involved, these have been added together with the 29 female respondents who were using the condom. Together, approximately one fifth of all condom users obtain it from a CBD agent (Figure II.4). However, it is important to note that amongst the 87 men who actually know of a CBD agent in their community and who use a condom, the CBD agent is their main source of supply (35 percent), followed by the shop (22 percent) and friends (17 percent).

\section{Figure II.4 Source of supply for condom users $(\mathbf{n}=\mathbf{2 0 1})$}

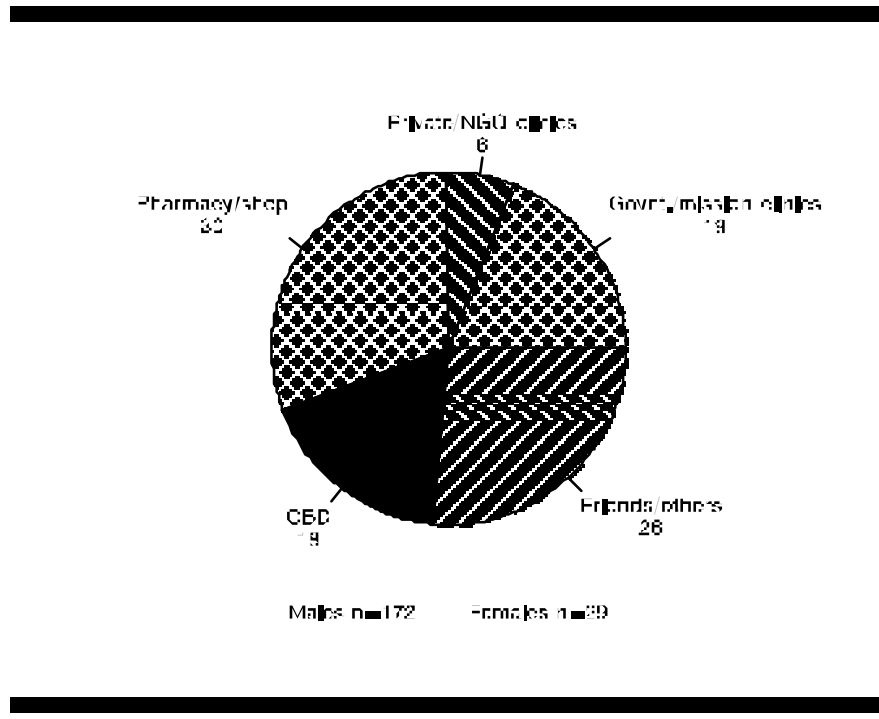

Together, these two findings imply

that if CBD agents make themselves known, people will use them as a source of supply for pills and condoms.

\section{d) Comparison of CBD and clinic clients}

It is of interest to programme managers to know something about the characteristics of the clients who obtain their method from CBD agents and how they compare with clients who use other sources, in particular clinical sources. A brief analysis was undertaken that compared female supply method users who obtained their method from a CBD agent with those whose source of supply was the clinic. To allow for a direct comparison to be made between similar types of users, we restricted the analysis to women who use a method which could be supplied by a CBD agent, and who know of a CBD agent in their community. These criteria were used so that it can be assumed that all the women have potentially equal access to the services a CBD agent provides, and thus any differences between them are not due to accessibility to a particular source or method used. Consequently, the analysis is based upon a sub-sample of 166 women who were currently using a supply method at the time of the survey (pill, condom or spermicide), who knew of a CBD agent in their community, and who obtained their method from either a clinic (public or private) or from a CBD agent ${ }^{14}$. The basic characteristics of this sub-sample are described below. 
As can be seen from Table II.1, women who have access to a CBD agent and use a supply method are somewhat more likely to get their method from a CBD agent than a clinic: the sample showed a 60-40 split in favor of CBD agents as the method source. The women using these two sources were then compared in terms of four basic characteristics: age, maritalstatus, parity, and religion. For all four characteristics there were no statistically significant differences between women using the two sources ${ }^{15}$. This finding suggests that women's choice of source is not influenced by their personal situations. Women may choose one source over another because of other variables not measured in this study such as perceived quality, cost or convenience. In particular, it appears that unmarried, youngerwomenare as likely to use a CBD agent as a clinic as a source, although both sources appear to be problematic for this category of user.
Table II.1 Characteristics of those women who use a supply method and know of a CBD agent

\begin{tabular}{|l|l|}
\hline \multicolumn{1}{|c|}{ Characteristic } & \\
\hline Mean / median age & 28 years \\
\hline Married & 86 percent \\
\hline Mean parity & 3.5 children \\
\hline \multirow{2}{*}{ Religion } & Protestant: 71 percent \\
& Catholic: 27 percent \\
\hline \multirow{3}{*}{ Source of method } & CBD: $58 \%$ \\
& clinic: $42 \%$ \\
\hline \multirow{2}{*}{ Programme } & CHAK: 38\% \\
& MYWO: 22\% \\
& FPAK: $19 \%$ \\
& NCC: $10 \%$ \\
& FLPS: $6 \%$ \\
& MOH: $5 \%$ \\
\hline \hline
\end{tabular}

\section{e) Provision of services to the youth and unmarried}

The vast majority of respondents felt that CBD agents should discuss family planning with youth ( 78 percent of women, 82 percent of men) and with those who are not married( 80 percent women, 86 percent men). CBD agents should not feel, therefore, that discussing family planning with the youth or unmarried is socially censured ${ }^{16}$. However, only six percent of female and seven percent of male respondents indicated that they have ever received any sex education from CBD agents. Moreover, the CBDagents' attitude toward providing contraceptives is clearly genderbiased; the vast majority ( 81 percent) said that they would provide contraceptives to an unmarried boy with no children, while only 26 percent said they would provide contraceptives to an unmarried girl who has not yet had a child or become pregnant. This bias was found to be stronger amongst CBD agents in the rural programmes. If an unmarried girl has been pregnant, however, the vast majority (96 percent) of agents said that they would have no problem supplying her with contraceptives. Clearly

15 Age and parity were compared using t-test and analysis of variance, and marital status and religion were compared using the chi-square test.

16 Current $\mathrm{MOH}$ family planning guidelines do not stipulate age, marital status or proven fertility as factors to consider in providing pills or condoms. 
the CBD agents are concerned and misinformed about the possibility of contraceptives influencing a woman's ability to conceive.

Responses from the unmarried youth ${ }^{17}$ interviewed confirmed that these attitudes translate into practice. Amongst this group (323 females, 178 males), 28 percent of the females and 35 percent of the males knew of a CBD agent, but only six percent of them ${ }^{18}$ had ever had a personal talk with the agent. Of the 23 percent of females and 44 percent of males in this group currently using a method, only eight percent got their current method from a CBD agent. The youth remain an under-served group for CBD programmes, in terms of both information on sexuality and contraception and provision of services.

\section{f) Provision of integrated services}

The vast majority of respondents ( 93 percent women, 87 percent men) favored the idea of CBD agents providing STD/HIV information and counseling. When asked which non-family planning activities they undertake, 41 percent of the CBD agents mentioned educating, counseling and referring clients to clinics for PHC/MCH services, and 31 percent mentioned referring for STD/HIV services. Asked if they themselves provide information and counseling on STDs/RTIs and HIV/AIDS, 94 percent claimed that they do. Indeed, more than half claimed to have provided information on HIV/AIDS (91 percent), gonorrhea (65 percent) and syphilis (55 percent) in the previous month. However, less than 15 percent of both male and female respondents indicated having ever received information on $\mathrm{PHC} / \mathrm{MCH}$ and other reproductive health services from $\mathrm{CBD}$ agents.

Amongst the men who know of a CBD agent, there is a clear split into two groups of programmes, those for which more than one-third of the respondents have ever received information on STD/HIV (the MOH/GTZ, CHAK and FLPS programmes), and those for which less than a quarter have ever received this information (the NCC, MYWO and FPAK programmes). For women, the division is not as distinct, although respondents living in the areas served by the MYWO and FPAK programmes appear to be less likely to have discussed these issues with a CBD agent.

Why this is so is speculative, but may be because the FPAK and MYWO programmes are the oldest and were set up explicitly for providing family planning information and services; consequently, they may be more deeply entrenched in an organizational model that cannot easily reorientate itself to expanding the range of services it provides. Certainly, as section III shows, they are among the most effective of programmes for providing family planning services, and this success may itself inhibit the organizations from moving into other, less well-known service delivery activities.

About half of the men and one-third of the women who know a CBD agent in the CHAK and $\mathrm{MOH} / \mathrm{GTZ}$ catchment areas have received information or referral services on immunization, children's

17 The WHO definition of youth was used, i.e. aged between 10-24 years. In this survey the age range was 15-24 years. 
nutrition, malaria prevention/treatment and diarrhoea treatment. This indicator suggests that the CHAK and MOH/GTZ programmes may be more integrated than the others.

\section{g) Impact of CBD work on female agent's life}

In addition to the impact that a CBD programme can have on the community's access to family planning information and services, the benefits and costs to the CBD agents of doing this work can also have an impact on themselves and their family. There has been considerable interest recently in finding out more about the impact of such work on the female agents' lives in particular, and so some data were collected from the 158 female agents on this issue.

A frequently voiced argument in relation to women acting as unpaid workers in CBD programmes is that, in view of women's generally disadvantaged economic situation when compared with men, their participation with little or no financial remuneration in organized programme activities is exploitative and contributes to their continued dis-empowerment. It is further argued that one reason for the difficulty in recruiting men as CBD agents is the unattractiveness of such low-paid work. A question remains, therefore, as to why female $\mathrm{CBD}$ agents continue to work with apparently such little material incentive.

Lily Kak and Suresh Narasimhan (Kak and Narasimhan, 1992) have proposed a framework for assessing the impact of this type of work on female agents' personal life. The framework proposes that employment by a CBD programme provides the agent with incentives such as training, limited income, and networking opportunities, which, it is hypothesized, will lead to the woman's selfenhancement, which in turn will empower the woman to have greater influence within the family and within the community. Using this framework in a multi-country survey of female family planning field workers, Kak and Narasimhan drew the conclusion that family planning fieldwork does provide an opportunity for womens' self-enhancement at the grassroots levels and increases their autonomy and decision-making power within their families and the wider community. The impact on the lives of the 158 female agents interviewed has been analyzed using the same framework.

While the agents in the NCCFP programme receive a salary and are treated as full-time workers, the part-time agents who are provided with an "allowance" in the FPAK, MYWO, CHAK and FLPS programmes cannot be said to be financially compensated for the work that they do, as the highest amount received is Kshs 600 per month (less than \$10). Moreover, some agents are expected to use this allowance to pay for their transport while attending monthly supervisory meetings, or to collect their contraceptive supplies. For those workers in the two programmes which give only nonfinancial incentives (MOH/GTZ and NCCS), there is clearly even less materialcompensation for their activities. What role the financial and non-financial aspects of the work played in their lives, how these factors affected the agents themselves, and their position in the family and community were explored.

\section{i) Self-enhancement}

The agents were asked to state what they liked and what they disliked most about their CBD work, what changes have taken place in their lives as a result of their CBD work, and for how long they 
would like to continue to work as CBD agents. The vast majority (96 percent) of female CBD agents were certain that the work had a positive impact on their lives, with only a very few agents feeling that the work had not made any difference. The agents gave a range of responses about what they liked most about the work; the most commonly mentioned "likes" were:

C providing education to the community (25 percent),

C helping women to plan their families (15 percent),

C speaking in public meetings (13 percent).

A substantialproportion (13 percent) were so enthusiastic about the work that they reported that they liked everything. About one-half of the respondents said that there is nothing they do not like about their work. Of those who did complain about the work, the majority said that they did too much work for little or no pay, while others mentioned the lack of other incentives. There was a significant difference between the programmes, however, with the FLPS programme having the lowest proportion of agents with complaints and the CHAK programme having the highest proportion. Yet both programmes have similar financial remuneration packages, and so it would appear that nonfinancial aspects may be behind the complaints.

There was a significant relationship between remuneration level and job satisfaction - more than three quarters of those who were paid a salary or allowance reported that there was nothing they did not like about their work, while for those who were not paid, only 39 percent said that there was nothing they disliked about the work. However, those who were paid were more likely to complain about the level of remuneration and incentives than those who were not paid. Only a small percentage (4 percent) were dissatisfied to the point that they wanted to quit the CBD work, or said that they would quit if remuneration was not increased.

\section{ii) Empowerment within the family and community}

The 112 agents who did receive some financial payment were asked how they spend the money; this was used as an indicator for personal empowerment within the family. Many different responses were given, but the vast majority said that they use it to meet the family's financial needs, such as household expenses ( 83 percent) and paying children's schoolfees ( 15 percent). Some also invest or save the money through banking (16 percent), using it for personal business ( 6 percent) or contributing to women's group activities (6 percent); 13 percent said that they use their allowance for their CBD work. Having this personal income does not necessarily mean that they have increased control over their family's resources, however - more than one-third said that their husbands still control these resources, and about one-half said that the work had not increased their decision-making power in the family or in the community.

The women were also asked whether they felt that their work as a CBD agent as a whole, and not only their additional income, had improved their relations and status within the family. The vast majority felt that the relationships with their husbands ( 92 percent) and their in-laws ( 85 percent) had improved because of the work. Most also felt that their influence in making decisions on the children's education ( 85 percent), on children's medical treatment ( 87 percent) and on household expenses (63 percent) had increased. These changes seem to be consistent across agents from all programmes, 
whether rural or urban-based ${ }^{19}$, or whether the agent was remunerated or not ${ }^{20}$. The agents from the CHAK and NCCS programmes, however, felt that there had been no change in their influence on making decisions for household expenses or on their ability to go out of the house without their husband's permission ${ }^{21}$. These findings suggest that it is the whole package of monetary and non-monetary benefits accrued from the CBD work which contribute to the women's sense of empowerment within the family, and not just the income.

About three quarters of the womensaid that their attitude toward their daughters had changed positively as a result of their CBD work and training. Of those who said that their attitudes had changed, the highest proportion (48 percent) expressed the view that they now understood the need for girls to be counseled about their sexuality; however, only about one-quarter now felt that girls are equal to boys.

Almost all (98 percent) agents felt that their relations with their neighbors had improved, and that they make a positive contribution to their communities, primarily through increasing people's knowledge and use of family planning. These perceptions are the same regardless of the type of programme, its location, or the agent's remuneration status. These selfperceptions were confirmed by the interviews with community members in their catchment areas; as described in section II, the vast majority of both male and female respondents who know of a CBD agent felt that the agent as well known and respected in the community.

These findings support those of the CEDPA study - the vast majority of CBD agents are satisfied with the work they do, regardless of whether they are paid or not paid, urban or rural-based, or the type of organization they work for. Therefore, although remunerating CBD agents increases their level of job satisfaction and influence in making decisions about household expenses, remuneration alone does not empower female CBD workers - the non-monetary benefits of CBD work play an equally important role.

The only exception was that those who were remunerated were more likely to say that their ability to influence decision-making on household expenses had increased. This is probably because their extra income contributes towards meeting the household's expenses and so this gives them a greater say in how the money is spent. had increased, although for those saying that it had not changed it is not clear whether they already felt free to do so or whether they still felt that they had to get permission. 


\section{PROGRAMME OUTPUTS AND EFFECTIVENESS}

\section{a) Recording and reporting programme outputs}

The four measures commonly used describing CBD programme outputs in Kenya are:
\# the number of new or revisit clients visited or met for family planning services;
\# the volume of contraceptives delivered by the agents;
\# the Couple Years of Protection (CYP) ${ }^{22}$ provided by the contraceptives delivered;
\# the number of effective referrals ${ }^{23}$ made for clients seeking clinical contraceptive methods ${ }^{24}$.

Data on these outputs for the year 1994 (the most recent year with complete data) were collected through staff interviews, examination of service records at the programme headquarters, and from a sample of CBD agents. Many CBD agents in Kenya are also trained to provide other services, such as STI and HIV/AIDS IEC and counseling and some MCH and public health care services. However, in 1994 although most programmes required their agents to record their non-family planning activities, these data were not routinely reported to the programme headquarters, and so it was not possible to measure these outputs at the programme level.

In the process of collecting data from both programme headquarters and individual CBD agents, a number of limitations in the recordkeeping and reporting systems became apparent. In addition to restricting the comparative analyses possible for this study, these limitations, listed in the box on the following page, have direct implications for the routine supervision, monitoring and evaluation functions of the CBD programmes themselves. Improvements in these recordkeeping and reporting system weaknesses would greatly enhance the programmes' capacities to function more effectively.

22 CYP calculations are made for individual methods and are based on the amount of each contraceptive needed to protect a couple from unwanted pregnancy for one year. The 1993 USAID guidelines were used: 15 cycles of pills, 150 condoms, 150 foam tablets and 6 tubes of jelly, are equal to one CYP. 


\title{
Limitations in data available due to variations in recordkeeping and reporting practices
}

\author{
1. Variations in definition of a "new client." FPAK, FLPS, CHAK and NCCFP defined a new client as any \\ person new to the CBD agent, while MYWO, MOH/GTZ and NCCS defined a new client as a completely \\ new family planning acceptor. Thus, the first group of programmes may include both new and continuing \\ users and the second group new users only.
}

2. Variations in the number of pill cycles and condom pieces supplied to new and revisit clients. The CBD programmes have different policies and practices on the number of pill cycles and condom pieces provided to new or revisit clients. Although the vast majority of CBD agents interviewed said that they supply one pill cycle to a new client and three cycles for return visits, there are some who give two or three cycles for both first and return visits. Because agents give different amounts of commodities with each visit, it is not possible to equate number of visits with the volume of commodities distributed. CYP is therefore a better comparative measure than the volume of clients visited/met, because the volume of clients' visited / met describes the total number of contacts a CBD agent has had with all clients to supply the commodities or refer for services, and not the number of clients served.

3. Incomplete records at the programme headquarters. Data on revisits and contraceptives distributed for the FLPS Nairobi site during the first quarter of 1994 were missing. Consequently, these data were estimated by assigning similar values to those available for the second quarter of 1994. This site also did not separate data for the CBD agents and the FLPS clinic, and so the CBD data were obtained by going through the clinic records and subtracting them from the total FLPS Nairobi output. Data on effective referrals data were also missing for this site due to poor record keeping. For the FPAK programme, one site was testing a new reporting system which does not differentiate between new visits and revisits by method type.

4. Variations in programme reporting systems.

C Unlike the other programmes, the CHAK and MOH/GTZ programmes do not keep separate records of the number of new and revisit clients by method provided.

Ç In 1994, the FPAK programme did not record effective referrals for Norplant ${ }^{\circledR}$ implants.

Ç The MOH/GTZ programme does not report effective referrals by method, thus making it impossible to compute the CYP for effective referrals.

C Only the MYWO keeps records of both effective and non-effective family planning referrals.

Ç All except the MOH/GTZ programme require their CBD agents to keep records of non-family planning referrals and IEC activities undertaken, but only the FPAK and MYWO programmes also keep records of these activities at the headquarters level.

C Only the FPAK and FLPS programmes require their CBD agents to record socio-demographic characteristics of their clients, but neither of these programmes record or report these data at the programme level.

5. Aggregation of injectables' records. All programmes' record Depo-Provera and Noristerat referrals in one category as 'injectables'; in calculating CYP, all injectables were assumed to be Depo-Provera as this is the most frequently provided injectable method in Kenya.

6. Incomplete recordkeeping by $\boldsymbol{C B D}$ agents. The quality of records kept by individual $\mathrm{CBD}$ agents varied between agents; only for the MYWO and MOH/GTZ programmes was recordkeeping up-to-date. For the FPAK and CHAK programmes, records kept at the headquarters were found to be different in some cases from those collected from the individual CBD agents; the agents tended to record fewer visits and commodities dispensed than indicated at the headquarters. For the FLPS, NCCS and NCCFP programmes, records for the individual CBD agents are not kept at the headquarters. 
It should be noted that although the remainder of this section focuses on describing programme outputs in terms of the indicators described above, whether these are the most appropriate indicators for a CBD programme is an issue for debate ${ }^{25}$. These indicators and the way they are reported do not adequately describe the full range of activities that the agents actually carry out. For example, the only interactions with community members that are reported are those that result in a service being provided, whereas interviews with the agents and their supervisors showed clearly that a substantial amount of their time is spent discussing family planning generally, as well as a myriad of otherreproductive and sexual health issues that are not recorded. Moreover, even though they have been trained and are expected to provide information and education on STIs and HIV/AIDS, there is no mechanism for reporting on these activities and so this aspect of their work tends to be undervalued by programme managers and ultimately the donors. Consequently, it is clear that not only do the existing recordkeeping and reporting systems require some strengthening to produce more valid data, the types of activities reportedand the indicators used to assess CBD programmes need to be reconsidered This may, in turn, require that the job descriptions of the agents be reconsidered to reflect more accurately the actual work that they carry out.

\section{b) Programme-level outputs}

Although the recording and reporting differences inhibit a thorough comparison across all programmes, some conclusions can be drawn from the data available. Programme-level outputs are described below for the number of clients met/visited, the volume of contraceptives distributed and CYP generated, and the number of effective referrals made and associated CYP.

\section{i) Number of clients met/visited by CBD agents.}

For all programmes, agents are required to report only those visits or meetings in which a contraceptive commodity is provided, that is, some CYP is generated. If they met a client to talk about family planning only this meeting should not be recorded. Table III.1 below shows that the FPAK programme is clearly reaching the most clients, with more than 450,000 contacts being made in 1994 . The table also confirms that for all programmes (except the NCCFP programme), CBD agents appear to be serving more revisits than new clients.

Data limitations prevent a full analysis of the method mix of each programme, but for those for which data are available, the method most frequently provided by the FLPS, MYWO and NCCS programmes is the pill (and in all cases the number of revisit clients exceeds the number of new clients), whereas for the NCCFP programme it is the condom (and the number of new clients is higher than revisit clients). The limited data that are available for the FPAK and MOH/GTZ programmes (not shown) and the volumes of commodities distributed, suggest that the majority of new clients recorded by these programmes are probably condom users. 
Table III.1 Number of clients met by programme and method in 1994

\begin{tabular}{|c|c|c|c|c|c|}
\hline \multicolumn{6}{|c|}{ RURAL VILLAGE DEPOT / HOME VISIT MODELS } \\
\hline Program & Type of client & Total & Pills & Condoms & Spermicides* \\
\hline \multirow[t]{2}{*}{ FPAK } & New clients & 186,314 & $\mathrm{n} / \mathrm{a}$ & $\mathrm{n} / \mathrm{a}$ & $\mathrm{n} / \mathrm{a}$ \\
\hline & Revisits & 271,631 & $\mathrm{n} / \mathrm{a}$ & $\mathrm{n} / \mathrm{a}$ & $\mathrm{n} / \mathrm{a}$ \\
\hline \multirow{2}{*}{$\begin{array}{l}\text { MOH/ } \\
\text { GTZ }\end{array}$} & New clients & 126,368 & $\mathrm{n} / \mathrm{a}$ & $\mathrm{n} / \mathrm{a}$ & $\mathrm{n} / \mathrm{a}$ \\
\hline & Revisits & 239,803 & $\mathrm{n} / \mathrm{a}$ & $\mathrm{n} / \mathrm{a}$ & $\mathrm{n} / \mathrm{a}$ \\
\hline \multirow[t]{2}{*}{ MYWO } & New clients & 99,306 & 51,214 & 47,173 & 919 \\
\hline & Revisits & 150,948 & 108,620 & 41,757 & 571 \\
\hline \multirow[t]{2}{*}{ CHAK } & New clients & 36,120 & $\mathrm{n} / \mathrm{a}$ & $\mathrm{n} / \mathrm{a}$ & $\mathrm{n} / \mathrm{a}$ \\
\hline & Revisits & 70,287 & $\mathrm{n} / \mathrm{a}$ & $\mathrm{n} / \mathrm{a}$ & $\mathrm{n} / \mathrm{a}$ \\
\hline \multicolumn{6}{|c|}{ URBAN CLINIC OUTREACH MODELS } \\
\hline \multirow[t]{2}{*}{ NCCS } & New clients & 30,252 & 14,910 & 14,675 & 667 \\
\hline & Revisits & 79,686 & 59,322 & 19,598 & 766 \\
\hline \multirow[t]{2}{*}{ NCCFP } & New clients & 32,337 & 3,849 & 28,488 & 0 \\
\hline & Revisits & 31,226 & 6,929 & 24,297 & 0 \\
\hline \multirow[t]{2}{*}{ FLPS } & New clients & 6,879 & 5,015 & 1,742 & 122 \\
\hline & Revisits & 9,358 & 5,950 & 3,356 & 52 \\
\hline
\end{tabular}

* Includes foam, jellies and creams

Although it is one of the smaller programmes, the NCCFP programme had the second highest absolute number of condom client visits and was the only programme with a higher level of condomgenerated than pill-generated CYP. In addition it had about five times more condom client visits than pill client visits. A possible explanation for this high number of condom clients is the practice of distributing condoms to groups of people in public meetings and the programme's focus on factories which have high numbers of workers. This presents the possibility of having many one-time-only clients who then get their regular supplies elsewhere, and illustrates another issue to bear in mind when interpreting these data.

\section{ii) Volume of contraceptives distributed and CYP generated}

Table III.2 shows that the rural programmes provide most of their CYP through the pill, although the difference between pill and condom-generated CYP is lowest for the MOH/GTZ programme. For the urban programmes, the distribution betweenmethods is eithermore equal (NCCS and FLPS) or heavily in favor of the condom(NCCFP). With the exception of the FPAK programme, spermicides are not widely used or distributed. 
Table III.2 Volume of contraceptives distributed and CYP generated by programme and method in 1994

\begin{tabular}{|c|c|c|c|c|c|}
\hline \multicolumn{6}{|c|}{ RURAL VILLAGE DEPOT / HOME VISIT MODELS } \\
\hline Programme & & Pills & Condoms & Spermicides & Total CYP \\
\hline \multirow[t]{2}{*}{ FPAK } & Amount & 467,749 & $2,747,129$ & 512,570 & \multirow[t]{2}{*}{54,079} \\
\hline & CYP & 31,183 & 18,314 & 4,582 & \\
\hline \multirow{2}{*}{$\begin{array}{l}\text { MOH/ } \\
\text { GTZ }\end{array}$} & Amount & 383,937 & $2,900,000$ & 34,103 & \multirow[t]{2}{*}{45,156} \\
\hline & CYP & 25,596 & 19,333 & 227 & \\
\hline \multirow[t]{2}{*}{ MYWO } & Amount & 370,773 & $2,522,154$ & 19,145 & \multirow[t]{2}{*}{41,660} \\
\hline & CYP & 24,718 & 16,814 & 128 & \\
\hline \multirow[t]{2}{*}{ CHAK } & Amount & 175,858 & 775,372 & 4,925 & \multirow[t]{2}{*}{16,926} \\
\hline & CYP & 11,724 & 5,169 & 33 & \\
\hline \multicolumn{6}{|c|}{ URBAN CLINIC OUTREACH MODELS } \\
\hline \multirow[t]{2}{*}{ NCCS } & Amount & 107,326 & $1,044,227$ & - & \multirow[t]{2}{*}{14,117} \\
\hline & CYP & 7,155 & 6,962 & - & \\
\hline \multirow[t]{2}{*}{ NCCFP } & Amount & 27,014 & $1,082,211$ & 0 & \multirow[t]{2}{*}{9,016} \\
\hline & CYP & 1,801 & 7,215 & 0 & \\
\hline \multirow[t]{2}{*}{ FLPS } & Amount & 28,982 & 184,233 & 4,090 & \multirow[t]{2}{*}{3,188} \\
\hline & CYP & 1,932 & 1,229 & 27 & \\
\hline
\end{tabular}

iii) Number of effective referrals and CYP generated.

Reporting effective referrals, that is, clients referredelsewhere for a method and who are known to have obtained the method, is clearly difficult and inconsistent. For example, the $\mathrm{MOH} / \mathrm{GTZ}$ programme requires its agents to only report the total number of referrals without identifying the specific method; the NCCFP agents tend only to report clients they refer to clinics other than the one to which they are attached, and thus the injectable and IUCD clients referred to their own clinics are not recorded; FPAK did not record Norplant ${ }^{\circledR}$ implants referrals in 1994; and the FLPS project was not able to provide data on any referrals for its Nairobi site.

The data on Table III.3 show that although the largest numberof referrals made by CBD agents tend to be for clients wanting to use the injectable, those clients referred for female sterilizations actually generate the highest levels of CYP, mainly because one referral for sterilization generates almost 50 times more CYP than one referral for an injectable. The relatively large number of vasectomy referrals by the FPAK agents is encouraging and the approaches used could perhaps provide a model for the other CBD programmes interested in reaching more couples with this male method. 
Table III.3: Effective referrals by programme, method and CYP in 1994

\begin{tabular}{|c|c|c|c|c|c|c|c|}
\hline \multicolumn{8}{|c|}{ RURAL VILLAGE DEPOT / HOME VISIT MODELS } \\
\hline Programme & & Injectable & IUCDs & Norplant & Vasectomy & Sterilization & Total \\
\hline \multirow[t]{2}{*}{ FPAK } & Clients & 17,854 & 5,018 & $\mathrm{n} / \mathrm{a}$ & 168 & 2,900 & 25,940 \\
\hline & CYP & 4,464 & 17,563 & $\mathrm{n} / \mathrm{a}$ & 2,100 & 36,250 & 60,377 \\
\hline \multirow[t]{2}{*}{ MYWO } & Clients & 11,547 & 2,390 & 267 & 23 & 1,801 & 16,028 \\
\hline & CYP & 2,887 & 8,365 & 935 & 288 & 22,513 & 34,986 \\
\hline \multirow{2}{*}{$\begin{array}{l}\text { MOH/ } \\
\text { GTZ }\end{array}$} & Clients & $\mathrm{n} / \mathrm{a}$ & $\mathrm{n} / \mathrm{a}$ & $\mathrm{n} / \mathrm{a}$ & $\mathrm{n} / \mathrm{a}$ & $\mathrm{n} / \mathrm{a}$ & 13,059 \\
\hline & CYP & $\mathrm{n} / \mathrm{a}$ & $\mathrm{n} / \mathrm{a}$ & $\mathrm{n} / \mathrm{a}$ & $\mathrm{n} / \mathrm{a}$ & $\mathrm{n} / \mathrm{a}$ & $\mathrm{n} / \mathrm{a}$ \\
\hline \multirow[t]{2}{*}{ CHAK } & Clients & 1,493 & 362 & 204 & 0 & 429 & 2,488 \\
\hline & CYP & 373 & 1,267 & 714 & 0 & 5,363 & 7,717 \\
\hline \multicolumn{8}{|c|}{ URBAN CLINIC OUTREACH MODELS } \\
\hline \multirow[t]{2}{*}{ NCCS } & Clients & 610 & 92 & 29 & 0 & 81 & 812 \\
\hline & CYP & 153 & 322 & 102 & 0 & 1,013 & 1,589 \\
\hline \multirow[t]{2}{*}{ NCCFP } & Clients & $\mathrm{n} / \mathrm{a}$ & $\mathrm{n} / \mathrm{a}$ & 73 & 0 & 366 & 439 \\
\hline & CYP & $\mathrm{n} / \mathrm{a}$ & $\mathrm{n} / \mathrm{a}$ & 256 & 0 & 4,575 & 4,831 \\
\hline \multirow[t]{2}{*}{ FLPS } & Clients & 67 & 12 & 47 & 1 & 15 & 142 \\
\hline & CYP & 17 & 42 & 165 & 13 & 188 & 423 \\
\hline
\end{tabular}

An interesting finding emerges when the levelof CYP generated through methods supplied by the CBD agents (see Table III.2) is compared with the level of CYP generated through methods referred (see Table III.3). For all except the FPAK programme, the CBD-supplied methods generate higherlevels of CYP than the methods for which clients are referred, which suggests that the programmes are having their biggest effect on fertility through the agents' role as a direct source of supply for certain methods ${ }^{\mathbf{2 6}}$. The FPAK programme (and probably the NCCFP programme ${ }^{27}$ ) demonstrates, however, that it is possible for the CBD agents to greatly increase their effectiveness by paying attention to promoting and counseling clients on clinicalmethods, and especially the permanent methods. The three other rural programmes work with populations similar to those served by the FPAK agents and so there would seem to be a possible "missed opportunity" for them to devote more time to discussing these methods with their clients.

26 From the perspective of the overall national family planning programme, however, attributing effective referral CYP to the CBD agent who makes the referral is, in effect, "double-counting" as the clinic supplying the method will also claim to have generated the CYP provided by the method.

27 The NCCFP CBD agents do not record clients who they accompany to their own clinics for the injectable and IUCD, and so these"referrals" are not reported. The true level of CYP generated through effective referrals is therefore much greater, and would possibly be as high as or higher than the CBD-generated CYP. 


\section{c) Average outputs per CBD agent}

The differences between programmes, in terms of the overall volume of clients met, contraceptives distributed and level of CYP provided, do not reflect the relative effectiveness of each programme as these output measures are clearly related to the number of CBD agents in a programme and to the way they operate. For comparing programme effectiveness, therefore, a more appropriate set of indicators would take account of the number of CBD agents providing the services, that is, the average annual outputs per CBD agent.

Table III.4 below describes a number of indicators of average annual output per CBD agent for 1994. These ratios were obtained by simply dividing the total values for each output by the total number of CBD agents in each programme; consequently, the data problems described earlier also apply to these findings. Several conclusions can be drawn.

\# First, regardless of programme type or location, all CBD agents see, on average, more revisit than new clients, and only a small proportion of their clients are referred for clinical methods. As was suggested in the previous section, however, this varies by contraceptive method. For the pill, the proportion of revisits to new clients is quite high, usually by a factor of two to four times (only the FLPS programme has an almost equalratio). For the condom, the agents in the FPAK, MYWO and NCCFP programmes all saw more new than revisit clients; this is probably because many condom clients may be one-time clients who get their regular supplies elsewhere.

Table III.4 Average annual client visits, referrals and CYP per CBD agent by programme and method

\begin{tabular}{|c|c|c|c|c|c|c|}
\hline \multicolumn{7}{|c|}{ RURAL VILLAGE DEPOT / HOME VISIT MODELS } \\
\hline \multirow[t]{2}{*}{ Programme } & \multicolumn{3}{|c|}{ Clients met } & \multirow{2}{*}{ Referrals } & \multicolumn{2}{|c|}{ CYP } \\
\hline & Total & New & Revisit & & CBD-supp. & referral \\
\hline FPAK & 624 & 254 & 370 & 35 & 74 & 82 \\
\hline MYWO & 202 & 80 & 122 & 13 & 34 & 28 \\
\hline CHAK & 203 & 69 & 134 & 5 & 32 & 15 \\
\hline MOH/GTZ & 88 & 30 & 58 & 3 & 11 & $\mathrm{n} / \mathrm{a}$ \\
\hline \multicolumn{7}{|c|}{ URBAN CLINIC OUTREACH MODELS } \\
\hline NCCFP & 1,445 & 735 & 709 & 10 & 205 & 110 \\
\hline NCCS & 428 & 118 & 310 & 3 & 55 & 6 \\
\hline FLPS & 222 & 94 & 128 & 2 & 44 & 6 \\
\hline
\end{tabular}


\# Second, agents in the urban-basedprogrammes are meeting more clients than agents in the rural programmes, which is not altogether surprising given that they generally live in more densely populated areas. The agents in the MOH/GTZ programme clearly have the lowest average outputs, but this is expected as the programme was explicitly designed to have a high number of fully voluntary but relatively low-performing agents per community.

\# Third, the CBD agents in two programmes, the urban-based NCCFP and the ruralbased FPAK programme, are clearly more effective overall; indeed, the average number of clients met by the NCCFP agents is probably amongst the highest in the world for any CBD programme. This may well be because NCCFP agents are full time, salaried employees, and because many of their client interactions appear to be for condoms whichtake a relatively short amount of time. However, the referrals made by the NCCFP agents also yield a high level of CYP - an average of 11 CYP per referral, compared with the 2-3 CYP per referral for the other programmes. (Though the figure is somewhat inflated by the exclusion of referrals for the IUD and injectable for the NCCFP program; including these methods which have lower CYPs would reduce the average CYP pre referral.)

The FPAK agents are part-time and provided an allowance, although the MYWO and CHAK programmes also function in this way. The agents in the CHAK, MYWO and the urban-based FLPS programmes have similar levels of productivity, although they do not provide similar levels of allowances for their agents. Some possible explanations for these differences in productivity are explored in a later section.

\# $\quad$ Fourth, the average CYP generated per client met for agent-supplied methods is between 0.12 and 0.20 . This indicator measures the ratio of the average amount of CYP that is generated for each time an agent meets with a client to provide a method ${ }^{28}$. For all programmes in this study, CBD agents only record those meetings for which they delivered contraceptive commodities, and so, in theory at least, each visit should generate some level of CYP. The highest level was achieved in the urban-based FLPS programme (0.20), followed by the rural-based MYWO programme (0.17), with the other programmes achieving between 0.12 - 0.17 CYP per client. The rural-based FPAK programme, which is the most effective on other measures, is actually the lowest on this indicator (0.12). Thus, it takes 5-8 meetings with clients to generate one CYP. Why there should be these differences between programmes is not clear; the most probable reason is that agents in the FLPS and MYWO programmes may give more pill cycles or condoms during each meeting.

It is not necessarily a helpful indicator for CBD programmes as many meetings between agents and clients are purely for information exchange or for other non family planning service delivery activities. However, if the non-service delivery meetings are excluded from the records then it is valid to use. 


\section{d) Comparative productivity of CBD and clinic programmes}

The productivity of CBD programmes relative to clinic-based programmes is of interest to programme managers, but was not addressed directly in this study. Findings from the population survey reported above suggested that, in their catchment areas, CBD agents appear to be a more important source for pill and condom clients than the clinics. Although data on clinic outputs in the areas covered by CBD agents were not obtained, some data collected from the CHAK programme on its clinics and CBD agents allow a crude comparison to be made.

\section{Of the 21 hospitals under} CHAK's management, nine are linked with CHAK's CBD programme. As Figure III.1 shows, in 1994 the 527 CBD agents located in these nine sites met more new and revisit clients, and generated more CYP for distributing pills, condoms and spermicides, than all 21 CHAK hospitals. The CBD programme produced 66 percent of all family planning clients met by both programmes and provided 70 percent of the total CYP generated for pills, condoms and spermicides. For all methods provided through the nine hospitals and their associated CBD agents, the hospitals contributed almost

\section{Figure III:1 Proportions of CBD vs clinic outputs for the CHAK programme, 1994}

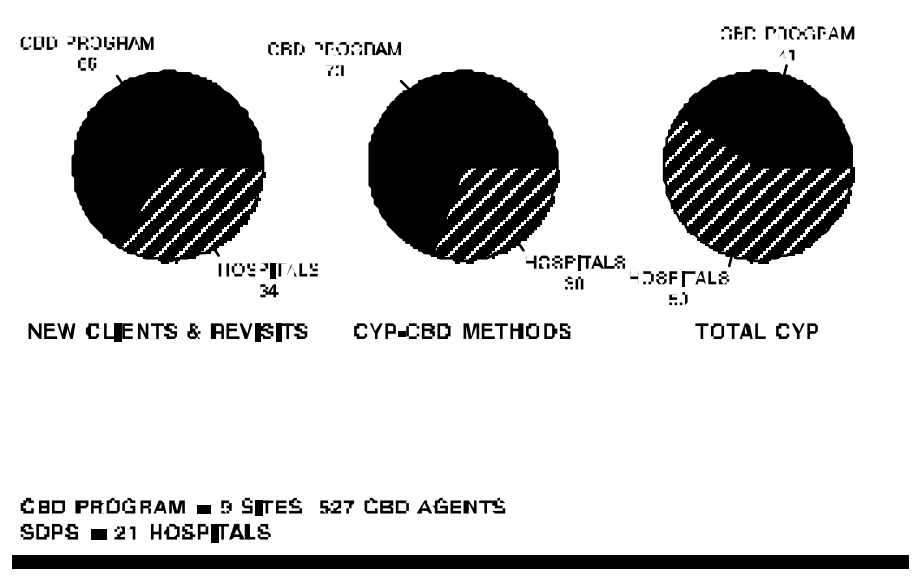
60 percent of the total CYP generated as would be expected.

\section{e) Factors determining programme performance}

Why CBD programmes perform differently is a key question, the answers to which can assist programme managers to understand their programmes better and can help policymakers better allocate resources. A number of factors which are frequently thought to contribute to these differences will be examined in this section, namely: the demand environment in which agents operate; agents' remuneration; supervision of CBD agents; the relationship between $\mathrm{CBD}$ agents and clinics in the same geographical area; the sex of the agent; and other socioeconomic characteristics of the CBD agents. The data for this section are drawn frominterviews with 199 CBD agents, with up to 20 CBD agents being interviewed in each of the study sites.

\section{i) Demand environment}

As shown above, programmes based in urban areas are more productive than those located in ruralareas, with the exception of the rural FPAK programme. Generally speaking, attitudes toward, use of, and consequently demand for family planning services are almost always higher for urban rather 
than rural populations, and thus urban-based agents are likely to find a more ready audience for their services. Moreover, urban areas have higher population densities, thereby facilitating easier access and communications between agents and clients and ensuring a larger potential client base from which to draw.

Within the rural areas, CBD agents were sampled according to whether they lived in an area with an existing high or low levelof contraceptive use (and, by implication, a high or low demand for their services), and their performance analyzed in terms of the mean CYP per agent for the agentprovided methods (see Figure III.2). These data indicate that for every programme except the CHAK programme, the agents located in the area with a higher contraceptive prevalence performed better than agents from the same programme in sites with a lower CPR. This finding
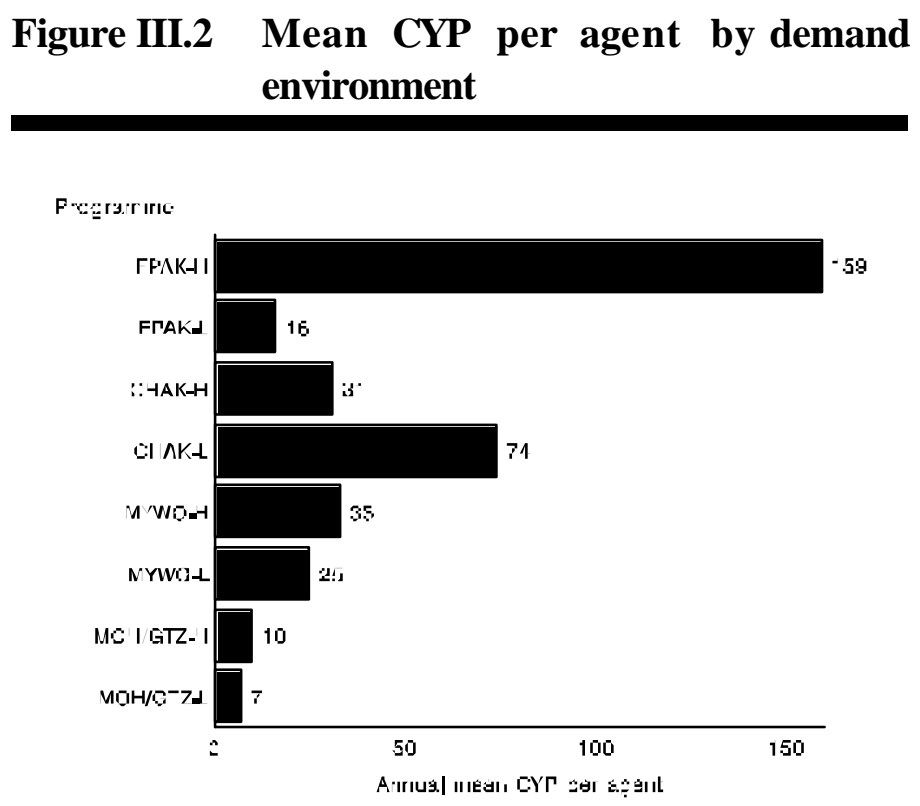
supports the expectation that the demand environment is a determinant of agent performance. For the CHAK programme, the probable reason for this difference was that the agents in the low prevalence site (Kericho) were being given an allowance, whereas those in the higher prevalence site (Meru) sites were not. This suggests that agent remuneration may also be a powerful determinant of performance and may override the influence of the demand environment.

\section{ii) Remuneration of CBD agents}

Remuneration of CBD agents has been one of the most highly debated issues throughout the evolution of the Kenyan CBD programmes. As described in Section I, a range of types of remuneration and/or incentive schemes are used by the programmes. The NCCFP programme is clearly the most effective of the three urban programmes, but it is also the only programme for which the agents are full-time, salaried workers, in effect outreach agents for the clinics. For the other two urban programmes, the NCCS programme, with agents given non-monetary incentives only, performed substantially better than the FLPS programme, whose agents are given a financial allowance.

Amongst the four ruralprogrammes, the programme that only provides non-monetary incentives $(\mathrm{MOH} / \mathrm{GTZ})$ clearly performed most poorly in terms of per agent effectiveness. The remuneration structures for the other three programmes are similar in that they all provide financialallowances to their agents (although CHAK's allowances are comparatively lower, and agents at some CHAK sites are not remunerated at all), but the agents in the FPAK programme consistently outperformed those in the MYWO and CHAK programmes. This would suggest that there are characteristics of the FPAK 
programme beyond remuneration that encourage its agents to perform better than their counterparts in the other programmes.

The relationship between level of remuneration and performance is not straightforward. Correlations were calculated between the level of personal remuneration and three output indicators (number of new and revisit clients met/visited; number of effective referrals; and CYP provided). The results indicate that there was a weak but significant positive relationship between level of remuneration and number of client visits made and amount of CYP provided, although there was no significant relationship with the number of clients referred. This supports the intuitive assumption that CBD agents who are remunerated would be more productive than those who are not, but the weakness of the relationship and the inconclusive results suggest that higherpay does not automatically lead to higher outputs.

Remuneration appears to influence agent satisfaction. When asked what they did not like about their CBD work, only half of the agents had complaints, but amongst those who did have complaints, too little pay and too much work (17 percent), working for no pay (15 percent), and strained relations with their spouse because of doing unpaid work ( 2 percent) did arise. These complaints were raised by CBD agents from all the programmes.

The non-monetary benefits gained from being a CBD agent may also influence performance. For example, off-site training is seen as giving agents an opportunity to visit other places and to meet with locally-based professionals, as well to acquire technicalknowledge in family planning and other health issues. Both factors provide them with status in their communities. In addition, the opportunity to interact directly with local leaders and the general recognition gained from community members were stated as reasons for taking on the work and for what they liked most about the CBD work.

\section{iii) Supervision}

Most successful CBD programmes around the world have strong management coupled with an efficient supervisory system. The importance of these factors was confirmed in this study: the four programmes with the highest average outputs per CBD agent (NCCFP, FPAK, NCCS and FLPS) all have supervisory systems that require the supervisor to have individual and group supervisory contacts with CBD agents on a monthly basis. A summary of the programme's supervisory structures is given in the box on the next page.

Guidelines for Kenyan CBD Programmes suggest that agents should have both an individual supervisory contact and one group meeting with their supervisors once a month (NCPD 1986:30). On average, most CBD agents reported receiving three supervisory visits in the previous three months, that is, receiving the suggested level of supervision, with the FLPS (10) and NCCS (6) agents having substantially more. More than one quarter (29 percent) of the agents interviewed, however, had not been visited at all in the last three months; most of these agents were with the $\mathrm{MOH} / \mathrm{GTZ}$ and MYWO programmes. A statistically significant relationship was found between the 
frequency of supervision and the agent's outputs ${ }^{29}$, leading to the conclusion that CBD agents who are supervisedmore frequently tend to meet with more clients. Asked if the frequency of supervisory visits should be more or less often, nearly one half (46 percent) of the agents were not happy with the current level, with most of these (91 percent) preferring more frequent supervision. Most of the agents who wanted more frequent visits were from the $\mathrm{CHAK}, \mathrm{MOH} / \mathrm{GTZ}$, and MYWO programmes.

29 This analysis excludes the FPAK agents because of confusion in responses between the role of the Field Worker, who is the agents' immediate supervisor, and the Supervisor, who supervises Field Workers. 
\# The NCCFP programme supervisors also have clinic duties and are not paid directly from the CBD programme. Although this arrangement does not provide many opportunities for the supervisors to supervise the agents in the field, each supervisor is responsible for only a few agents and all CBD agents report to the clinic every morning, which facilitates daily monitoring of individual CBD activities. Moreover, the CBD agents make a monthly activity schedule which they give to their supervisor.

\# The supervisors in both the NCCS and FLPS programmes are programme staff with no other duties and report directly to the Project Manager. These supervisors are expected to be in the field daily, except when they have record keeping activities at the clinic or project office. They make monthly schedules to plan visits to individual CBD agents and to plan monthly joint IEC and commodity resupply meetings with groups of CBD agents.

In the NCCS programme, supervisors work closely with local leaders to organize group IEC and contraceptive distribution activities, and regularly hold meetings involving local leaders, CBD agents and project staff (including the manager) to discuss project progress and problems. This interaction with local leaders creates an enabling environment for continuous cooperation between programme staff, local leaders and their communities, and CBD agents. It also allows community leaders the opportunity to monitor, albeit indirectly, the activities of CBD agents. Despite the high turnover rate amongst NCCS CBD agents and their non-remuneration, the NCCS agents perform relatively well, and this may be partly attributable to this high level of community interaction.

The FPAK and MYWO programmes have similar supervision structures, but different operating procedures. FPAK has full-time Field Workers each supervising about $15 \mathrm{CBD}$ agents, who report to district-level Supervisors, who in turn report to the Area Manager, who has responsibility for managing all FPAK activities at the area/provincial level. Area Managers report to the Programme Officer at headquarters. MYWO has full-time Divisional Coordinators with a medical training background who report to District Coordinators, who in turn report directly to the Family Planning Manager at the headquarters. Until 1994, MYWO did not have the equivalent category of the FPAK Field Worker, but has since adopted the policy of full-time paid Supervisors reporting directly to the Divisional Coordinator.

FPAK field workers and supervisors have more individual contact with CBD agents on a monthly basis than the MYWO divisional and district coordinators, including a full day meeting between the supervisor, field workers and CBD agents, and monthly visits to CBD agents individually. The MYWO District Coordinator relies mostly on reports and records from the Divisional Coordinator and has little or no contact with individual or groups of CBD agents. The MYWO Divisional Coordinators hold monthly meetings with groups of CBD agents.

Each site in the CHAK programme has two "motivators" based at the clinic who are the immediate supervisors for the CBD agents. They also have clinical responsibilities, but are directly answerable to the CBD Facilitator for their CBD work. The CBD Facilitator is a trained nurse who works full-time overseeing 15-65 agents at each site, and reports to both the Family Planning Nurse Coordinator at the clinic and the Health Services Director at the CHAK headquarters.

The Supervisors for the MOH/GTZ programme are the medical staff based in the nearest MOH clinic and are not paid separately for their CBD supervisory work, which may make it difficult for them to give sufficient attention to individual CBD agents. The CBD agents meet their supervisor on a monthly basis at the clinic but the supervisors do not make visits to individual agents as there are too many CBD agents per supervisor. The supervisors send their reports directly to the MOH/GTZ office in Nairobi. 


\section{iv) Sex of the CBD agent}

An OR study undertaken by FPAK (FPAK \& The Population Council, 1994) showed that involving males in CBD activities as distributors and as clients increased condom use by males and levels of inter-spousal communication on family planning. It is encouraging to note that most CBD programmes have recruited some men as agents, although they are still the minority. Section II showed that CBD agents are reaching both males and females in their catchment areas, but whether the sex of the agent makes a difference is an important issue.

Programme-level data cannot address this issue because none of the programmes disaggregate their services statistics by sex of the client. Amongst the 199 CBD agents interviewed, however, 41 were males and so it was possible to look at the relationship between the sex of the agent and their outputs.

The analysis indicated that, overall, there is a relationship between the sex of the agent and the number of clients visits/meetings, and the CYP generated from agent-supplied methods. Female CBD agents had, on average, highernumbers of clients (304 versus 152) and providedhigherlevels of CYP (51 versus 29) than male CBD agents.

Two sites had only female CBD agents, however, and so if these are excluded from the analysis, it is possible to compare female and male agents working in essentially the same conditions. As shown in Figure III.3, in five of the eight sites the male agents provideda mean level of CYP about the same as or higher than their female counterparts (these differences were not statistically significant). Whether their clients are predominantly men or women cannot be known from the service statistics, however.

Data collected from the catchment
Figure III.3 Mean CYP provided by sex of agent and demand environment

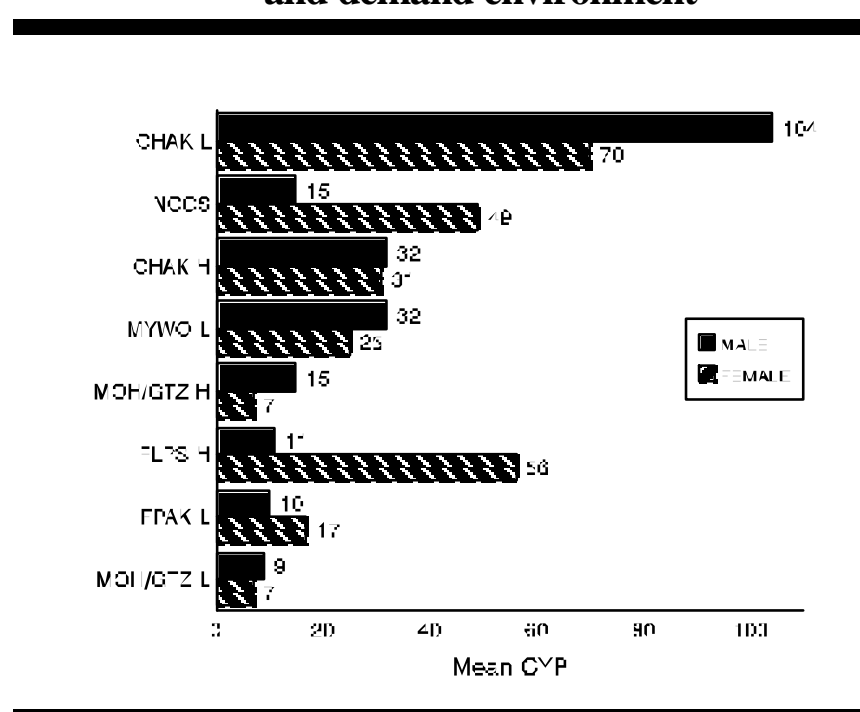
area populations (and reported in Section II) indicate that a higher proportion of men than women reported getting methods from the CBD agent in the high demand sites for the MOH/GTZ and CHAK programmes (which also had a comparatively high percentage of male CBD agents), but whether they obtained their method from a male or a female agent is not known. It appears, therefore, that male CBD agents are at least as active as female agents in reaching clients, but whether they tend to serve clients of their own or eithersex is not clear. 


\section{v) Relationship between CBD agents and referral clinics}

All except the MYWO programme have their own clinics to which clients can be referred ${ }^{30}$, although even in programmes with their own clinics agents do refer their clients to other clinics. When questioned about the nature of their working relationships, both CBD agents and clinic staff stated that they were good in all aspects. There was no difference in the perception of this relationship between high and low performing agents. Although a quarter of the clinic staff said that they didn't feel that CBD agents were competent, the vast majority (91 percent) indicated that they had an established relationship with the CBD agents in their area, and 86 percent of these described their relationship as good.

Clinic staff interviewed seemed to understand the role and function of CBD agents and of the referral system. Methods of making the referral seem to vary:

\# more than one half the clinic staff (56 percent) reported that CBD agents give referralcards to their clients which are then signed when the service has been provided and a section of the card is given to the client to take back to the CBD agent;

\# over one quarter of clinic staff mentioned that the CBD agents personally bring the client to their clinic;

\# and 18 percent of the clinic staff indicated that the CBD agents give verbal, rather than written, referral messages to their clients.

These three referral mechanisms were mentioned by staff from clinics in all study sites, i.e. agents in the same program would use different referral mechanisms. Agents may use whatever approach they feel is most appropriate for the client, the method preferred by the clinic, or whatever is easiest for the client. According to the clinic staff, CBD agents refer clients not only for contraceptive supplies and checkup, but also for MCH services, malnutrition, pregnancy tests, other illnesses and STD/HIV diagnosis and treatment.

Most (87 percent) staff from clinics with an established CBD referralsystem reported that there have been no problems that they know of with the referral system; indeed, almost half the staff reported that they also refer their clients to the CBD agents. However, almost one third of the CBD agents said that some of their clients had complained to them about bad treatment at the clinic, including denial of some of the services for which they were referred, rudeness from clinic staff, long waiting times, clinic staff failing to honor a referral card, and having to buy medical supplies before getting a service.

vi) Personal characteristics of $C B D$ agents

Significant differences were found betweenagents from the different organizations in terms of their educational, marital and religious characteristics (see Table III.5), but there

30 In a few FPAK CBD sites, the agents have to refer their clients to the nearest MOH clinic as there is no FPAK clinic in the vicinity. 
was no difference in the agent's average age. The urban-based programmes, and the rural MYWO programme, tended to have better educated agents, with 58-68 percent having secondary or above education. Although the majority ( 72 percent) of agents overall were Protestants, one-third of the agents in the three urban-based programmes were Catholics. Most agents ( 78 percent) were married monogamously, although one-third of the agents in the MOH/GTZ programme were in a polygamous marriage which reflects the norms of this part of Western Kenya.

To find out whether their personal characteristics influence an agent's performance, the relationships between these characteristics and the three output indicators were analyzed. All relationships were found to be very weak, suggesting that an agent's age, educational level, marital status and religion make very little difference to their productivity.

Table III.5 Percent Distribution of CBD Agents by Selected Personal Characteristics According to Programme

\begin{tabular}{|c|c|c|c|c|c|c|c|}
\hline & $\begin{array}{l}\text { FPAK } \\
n=40\end{array}$ & $\begin{array}{r}\text { MYWO } \\
n=40 \\
\end{array}$ & $\begin{array}{c}\mathrm{MOH} / \\
\mathrm{GTZ} \\
\mathrm{n}=40\end{array}$ & $\begin{array}{c}\text { CHAK } \\
n=40\end{array}$ & $\begin{array}{l}\text { FLPS } \\
n=19\end{array}$ & $\begin{array}{c}\text { NCCFP } \\
\& \text { NCCS } \\
n=20\end{array}$ & $\begin{array}{l}\text { ALL } \\
n=199\end{array}$ \\
\hline \multicolumn{8}{|c|}{ AGE } \\
\hline $20-29$ & 16 & 20 & 10 & 8 & 21 & 10 & 14 \\
\hline $30-39$ & 45 & 53 & 56 & 55 & 52 & 60 & 53 \\
\hline $40-49$ & 35 & 25 & 33 & 31 & 27 & 20 & 30 \\
\hline $50+$ & 5 & 3 & 3 & 8 & 0 & 10 & 5 \\
\hline Mean age & 38 & 36 & 38 & 39 & 35 & 38 & 37 \\
\hline \multicolumn{8}{|c|}{ EDUCATION } \\
\hline None/primary & 53 & 43 & 58 & 53 & 32 & 40 & 48 \\
\hline Secondary/tertiary & 48 & 58 & 43 & 48 & 68 & 60 & 52 \\
\hline \multicolumn{8}{|c|}{ RELIGION } \\
\hline Catholic & 23 & 10 & 18 & 15 & 32 & 35 & 20 \\
\hline Protestant & 70 & 80 & 73 & 85 & 63 & 45 & 72 \\
\hline Other & 8 & 10 & 10 & 0 & 6 & 20 & 8 \\
\hline \multicolumn{8}{|c|}{ MARITAL STATUS } \\
\hline Monogamous & 80 & 85 & 65 & 90 & 68 & 70 & 78 \\
\hline Polygamous & 8 & 3 & 33 & 5 & 11 & 0 & 11 \\
\hline Single & 3 & 5 & 0 & 0 & 16 & 10 & 4 \\
\hline Ever married & 10 & 8 & 3 & 5 & 5 & 20 & 8 \\
\hline
\end{tabular}




\section{IV: COST AND COST-EFFECTIVENESS OF CBD PROGRAMMES}

\section{a) Introduction}

The cost analysis had three objectives:

i) to calculate the total costs for each programme according to major cost categories;

ii) to estimate the unit cost per selected output for each programme;

iii) to compare the cost-effectiveness of the different programmes.

The analysis focused on the costs of providing services incurred by the CBD organizations themselves, i.e. the programme costs. The financial costs to the client of receiving the services were not considered for two reasons. Firstly, the services are provided for free in all programmes, and secondly, all programmes operate at the community level and so it is reasonable to assume that any travel costs incurred by a client would be minimal and approximately equal for all programmes.

Data were collected from the organizations' headquarters for the year 1994, the most recent year for which complete financial records were available. Data were collected using individual interviews with key personnel(e.g. programme officers / managers, accountants and supplies officers), and abstraction of financial records.

For all organizations, the CBD programme is only one component of their overall activities, and thus several items have joint costs, that is, costs shared between the CBD programme and other programmes within the organization. The percentage of an item's total cost that was incurred by the CBD programme was calculated based on estimates provided by the staff interviewed.

The cost categories were divided into capital and recurrent $\operatorname{costs}^{31}$. Capital costs describe those items in a programme which are purchased once only and have an expected useful life of more than one year; examples include equipment, vehicles, buildings and basic training. Recurrent costs are those items which are purchased regularly as they have useful life of less than one year; examples include materials, contraceptive supplies and staff time. A full description of these cost categories and their calculation for this study is given in Appendix Two.

Contraceptive commodities are a specialtype of recurrent cost because all contraceptives are currently donated free of charge to the organizations, via the MOH logistics management system, by internationalagencies. Following conventional practice, the cost which the organization would have had to pay if it was to actually purchase these contraceptives is included as a recurrent cost in the analysis. This is done to give a more accurate picture of the true economic cost of providing the total service, because these inputs are critical. 


\section{b) Costs of CBD programmes}

\section{i) Total programme costs}

Table IV.1 presents the total costs in Kenyan shillings for each of the seven CBD programmes for 1994. These costs are based on the assumptions and cost annualization procedures described in Appendix Two. The validity of these calculations was tested through a sensitivity analysis, the results of which are given in Appendix Two, and were found to be sufficiently robust. As the table shows, the most costly programmes are those that are the large-scale rural programmes, which have the largest number of CBD agents and the biggest catchment areas to cover. In US dollar terms, these annual costs vary from $\$ 714,000$ for the MYWO programme to $\$ 59,600$ for the FLPS programme (using an exchange rate of $\$ 1=56 \mathrm{Kshs}$ ). In themselves these figures are not particularly useful, and so the remainder of this section will focus on the distribution of costs by cost category and by capital and recurrent costs.
Table IV.1 Total costs of CBD programmes in 1994

\begin{tabular}{|l|l|}
\hline \multicolumn{1}{|c|}{ Programme } & \multicolumn{1}{c|}{ Cost (Kshs) } \\
\hline MYWO & 39.96 million \\
\hline FPAK & 33.78 million \\
\hline MOH/GTZ & 33.49 million \\
\hline CHAK & 11.53 million \\
\hline NCCS & 9.01 million \\
\hline NCCFP & 6.22 million \\
\hline FLPS & 3.34 million \\
\hline
\end{tabular}

\section{ii) Cost categories}

Table IV.2 below breaks down the total cost for each programme by the major cost categories. The results showclearly that programme staff are proportionately the highest costs currently incurred by all programmes. If contraceptive commodities had to be purchased, however, these would make up anything from 20 to 40 percent of a programme's total budgetand would become the largest cost for the FPAK and NCCFP programmes.

Table IV.2 Percent Distribution of Programme costs by major category in 1994

\begin{tabular}{|l|c|c|c|c|c|c|c|}
\hline & FPAK & FLPS & CHAK & $\begin{array}{c}\text { MOH/ } \\
\text { GTZ }\end{array}$ & MYWO & NCCS & NCCFP \\
\hline Contraceptives & 37 & 20 & 28 & 29 & 22 & 35 & 42 \\
\hline Programme staff & 35 & 35 & 33 & 46 & 31 & 38 & 28 \\
\hline CBD agents & 13 & 13 & 11 & 0 & 15 & 0 & 19 \\
\hline Materials & 4 & 14 & 4 & 16 & 8 & 5 & 4 \\
\hline Transport ${ }^{1}$ & 7 & 12 & 17 & 4 & 18 & 7 & 5 \\
\hline Training & 1 & 1 & 1 & 1 & 3 & 0.4 & 2 \\
\hline Other costs & 4 & 5 & 6 & 3 & 4 & 15 & 1 \\
\hline
\end{tabular}

$1=$ Fuel, maintainence and public transportation

2 = Includes other capital costs (e.g., furniture, equipment, vehicles and buildings) and utilities. 
Other findings shown in this table to be highlighted include:

! Remuneration of CBD agents, throughallowances and salaries, takes 11 to 19 percent of the budget for those programmes which give financial remuneration.

! Costs incurred for CBD training are a small proportion of the total program costs for all programmes. Although basic training is an important input during the initiation of a new programme, and refresher training important in maintaining quality during a programme's operations, on an annual basis it takes a very small proportion of the total costs.

! Transportation costs are a substantial proportion of the annual costs for the MYWO and CHAK programmes. These high costs are probably attributable to their supervision systems which require headquarters staff to make several supervisory visits to the field.

! The "other costs" category for the NCCS programme is comparatively high, probably because it is a small programme but has a lot of its own equipment, such as a computer and vehicle.

! Materials take up a large proportion of the MOH/GTZ and FLPS programme budgets. The $\mathrm{MOH} / \mathrm{GTZ}$ programme provides a large number of materials to its agents, partly in lieu of a financialremuneration, and the FLPS programme supplies its agents with a lotofIEC and other materials for delivering services.

1) Capital and recurrent costs. A distinction between the proportion of the total costs allocated to capital and recurrent costs is useful when planning whether and how a programme could expand. This is because it is usually the recurrent costs (which are variable and depend heavily on the amount of services provided) that will increase more than the capital costs when an existing programme expands its operations. Consequently, programmes with a lower proportion of their costs being spent on recurrent items normally have the potential to expand more easily. From the cost analysis, it appears that six ofthe programmes had over 94 percent of their costs spent on recurrent items; the one exception is the NCCS programme, which spends 85 percent. This programme would seem to be likely to be able to expand most efficiently. Conversely, programmes with a low proportion of their total costs going to capital items do not require high levels of fixed capitalexpenditures to operate, and so can probably absorb fluctuations in their annual operating budget more easily. 
2) Headquarters and field costs. As expected, the proportion of costs spent in the field were generally greater than those incurred at headquarters, ranging from 99 percent for the FPAK programme to 44 percent for the MOH/GTZ programme. Part of the explanation for the range in distributions between programmes maylie, however, in the definitions used. For example, the FPAK programme has decentralized much of its operationalresponsibilities to its District offices, and so much of what other programmes would classify as "headquarters" (i.e. management) costs are categorized as "field" costs. The MOH/GTZ headquarters proportion is high because it currently has a high level of staff costs at the headquarters, due in part to having expatriate staff acting in an advisory capacity.

\title{
c) Cost-effectiveness analysis
}

A cost-effectiveness analysis (CEA) was undertaken to compare alternative models for providing family planning services through CBD agents. It is important to note that this CEA uses data for one year only (1994), and thus does not look at changes in costs and outputs over time. A CEA produces a cost-effectiveness ratio for each CBD programme in terms of the total cost per unit of output. The definition of output is therefore extremely important as it must be an output which can be compared across all seven programmes. Data on several outputs were collected, but difficulties were encountered with two programmes (the MOH/GTZ programme and the Nairobi component of the FLPS programme) in providing data on effective referrals and CYP for referralmethods, and so these output measures are not included.

The two ratios presented below are 'crude' unadjusted ratios that have been computed by simply dividing the total CBD programme costs by the total value of the output because the data available were of insufficient quality to calculate 'adjusted' ratios as proposed in the box below.

\section{Calculating cost-effectiveness ratios}

\begin{abstract}
Janowitz and Bratt (1994) suggest two ways in which these ratios could be calculated. Both approaches require that programme costs can be accurately allocated, either to the process of distributing one unit of a contraceptive method, or to the costs of undertaking one visit / meeting. In addition to those item costs (e.g. commodities) which can be allocated completely to a specific method or visit, a proportion of the joint recurrent and capital cost items need to be allocated to each method or visit, which is extremely difficult to do. Janowitz and Bratt recommend identifying one key programme item as the "allocation variable," calculating the joint cost proportions for this item, and then using these proportions to allocate the total programme costs. For this analysis, the agents' time is used as the key programme item, and so agents were asked to define how they allocated their time between different activities. Unfortunately the responses given were of extremely low validity and so have had to be abandoned.
\end{abstract}

Another approach is to use an agent's total outputs as the allocation variable, and to make cost allocations based on the proportions contributed to the total outputs by each activity, on the assumption that costs incurred are directly related to the volume of each output produced. Although far from ideal, the total programme cost allocated for each CEA ratio has been made under the following assumptions. For the cost per total client visits, it was assumed that CBD agents spend virtually all their time visiting or meeting clients for family planning information and services, and that minimal time is spent on other activities. It was further assumed that other programme costs are all incurred in support of the CBD agents' family planning activities, and so they were also allocated to supporting family planning visits / meetings. For the cost per CYP, a crude "allocation" technique was used by assuming that all programme costs ultimately go toward providing contraceptives, although in reality CBD agents spend time on referrals for FP and other non-FP activities and on IEC activities. 
Consequently, the two cost-effectiveness ratios which are comparable across most of the programmes are presented.

\section{i) Cost per client met/visited}

Figure IV.1 indicates that most programmes are able to limit the costs of meeting clients to Kshs 70 - 106 (i.e. \$1.3 - \$1.9) per client met. Two programmes, however, appear to be less cost-effective when measured by this ratio, with the rural MYWO programme costing Kshs 148 (\$2.6) and the urban FLPS programme Kshs 204 (\$3.6) per client met/visited. These higher cost-effectiveness ratios are probably due to the fact that these two programmes had the highest level of programme operating costs (see Table IV.2) which, when combined with the fact that their agents are only in the mid-range of effectiveness in terms of number of clients met (see Table III.4), leads to a low cost-effectiveness ratio.

\section{ii) Cost per agent-supplied CYP}

Figure IV. 2 describes the cost per CYP generated by those methods supplied by CBD agents. Given the unadjusted approach used to calculate the costeffectiveness ratios it is not surprising to see a similar pattern across the programmes, i.e. five programmes have approximately similar levels of costeffectiveness (\$11.2 - \$13.5) and two programmes being substantially less costeffective. This finding confirms that rural and urban CBD programmes can achieve similar levels of cost-effectiveness, and that for the less cost-effective programmes the reason is not because of where they operate.

Although the NCCFP programme was shown to have the highest outputs per CBD agent (see Table III.4) and is quite cost-effective on both ratios, it is not the most cost-effective programme. This may be partly because of the relatively high proportion of programme costs allocated to agent remuneration (19 percent) compared to the other programmes which remunerate their agents. For example, the NCCFP agents produce more than double the output per agent of the FPAK agents, but

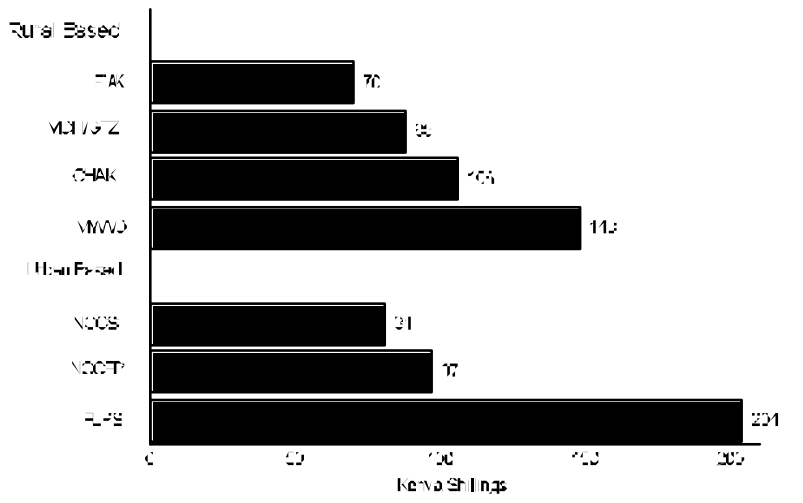

Figure IV.2 Cost per CBD-CYP (1994)

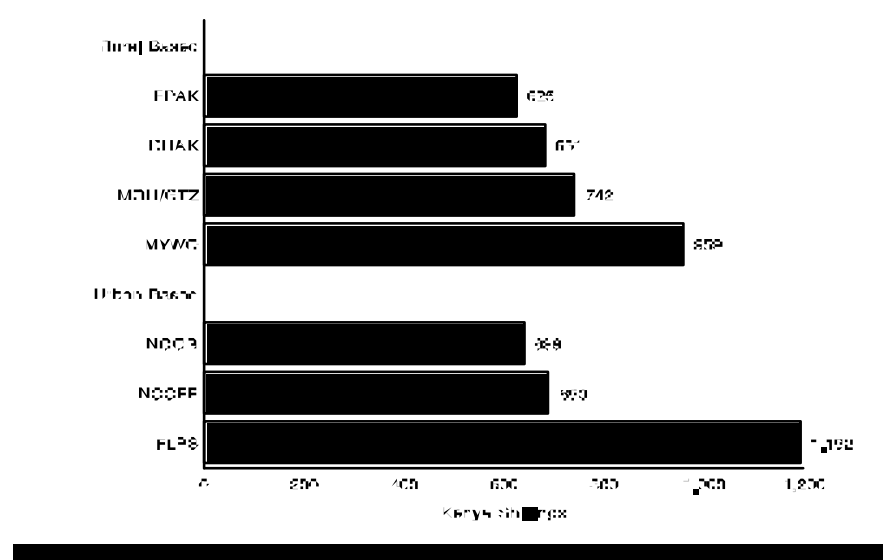


they also receive more than triple the remuneration of the FPAK agents. Conversely, the MOH/GTZ programme had the lowest outputs per CBD agent, but the programme incurs no costs for CBD remuneration; its overall cost-effectiveness ratios are, therefore, relatively low.

There are two possible explanations for the relatively high cost-effectiveness ratios for the FLPS programme. First it is a small programme (although the NCCFP programme has fewer CBD agents) which means that it cannot enjoy the economies of scale of the larger programmes. Secondly, in 1994 its Kisumu site had only recently started operating and so may have been incurring initialstart-up costs. The small proportions of total costs allocated by FLPS to capital costs (3.9 percent) and headquarters costs (3.5 percent) for 1994, however, do not give strong support to this possibility.

The MYWO and CHAK programmes are much older and larger programmes operating CBD models similar to the FPAK programme, but they have relatively higher cost-effectiveness ratios. This may be due to, among other factors, their supervision systems described in section III. Both supervisory systems appear to be less effective, which contributes to a relatively low output per CBD agent (compared with the similar FPAK programme). The supervisory systems are also more costly, in that the MYWO and CHAK programmes use both a larger proportion (18 percent and 17 percent respectively) and an absolute amount of their totalbudgeton transportation than the FPAK programme. The FPAK and CHAK programmes spent about the same absolute amount on transportation but the FPAK programme covered a larger geographical area and had more agents; the MYWO programme has twice as many agents in fewer sites than the FPAK programme but spent three time as much on transportation. 


\section{V: QUALITY OF CARE PROVIDED BY CBD PROGRAMMES}

\section{a) Measuring quality of care}

To measure the quality of care provided by the CBD programmes, this study was guided by the indicators proposed by the Service Delivery Working Group of the USAID-funded EVALUATION Project (The EVALUATION Project, 1993). The Working Group proposed 38 indicators organized according to the six elements of the Bruce-Jain framework (Bruce, 1990), although the Group acknowledged the limitations of applying this framework to a CBD rather than a clinical setting. The results presented in this section will also be organized according to this framework.

The most frequently used methods of collecting data on service quality are observations of client-provider interactions and exit interviews with clients, but these could not be used in this study because of resource constraints. Instead, data collected during the catchment area survey from respondents who indicated that they obtained their current method from a CBD agent have been used. It is acknowledged that such retrospective data may be less valid than data collected through directly observing the client-agent interaction and/or interviewing clients immediately after such an interaction, but it is felt that the data available from the 98 interviews with clients who were current $\mathrm{CBD}$ agent clients is sufficiently valid (see Table V.1).

\section{Table V.1 Number of CBD clients interviewed by programme and method used}

\begin{tabular}{||l|c|c|c||}
\hline Programme & Pill & Spermicide & Condom \\
\hline FPAK & 10 & 0 & 1 \\
\hline MYWO & 16 & 1 & 2 \\
\hline MOH/GTZ & 5 & 0 & 0 \\
\hline CHAK & 46 & 0 & 2 \\
\hline FLPS & 4 & 0 & 0 \\
\hline NCC & 11 & 0 & 0 \\
\hline ALL & $\mathbf{9 2}$ & $\mathbf{1}$ & $\mathbf{5}$ \\
\hline
\end{tabular}

It should be noted that most of the respondents were using the pill, that the $\mathrm{CHAK}$ programme is over-represented in this sample, and that for the respondents in the NCC catchment area it was not possible to distinguish whether they had been served by an agent from the NCCS or NCCFP project as both operated in the same area. Information collected from programme records, through interviews with programme staff and CBD agents, from CBD agent records and from an inventory of the agents' equipment and supplies are also used. 


\section{b) Interpersonal relations}

This element is difficult to measure accurately, even with direct observation of the client-agent interaction. All programmes appear prepared to address this issue because they all report that "good interpersonal skills" was one of the criteria they use when recruiting CBD agents and that training included developing a good interpersonal relationship with clients. When asked, 74 percent of the CBD clients reported having been given the opportunity to ask questions during counseling, which is one indicator suggesting that interpersonal relations are probably satisfactory.

\section{c) Choice of method}

To provide a quality service, a CBD agent should be able to offer a wide choice of methods (directly or through referral), and should discuss several methods with the client to help them make an informed choice. All the CBD programmes allow their agents to distribute combined pills, condoms, and spermicides (foam tablets, creams and jellies), and to refer their clients to clinics for clinicalmethods and medical checkups. Moreover, the national CBD curriculum includes training in both clinical and non-clinical methods.

While the vast majority of the CBD agents who were intervieweddid have supplies of pills (95 percent) and condoms ( 85 percent) available, very few had any spermicides; only 28 percent of the agents (all from the FPAK and FLPS programmes) had foaming tablets, and none had jellies or creams. This places a limit on the range of methods directly available to clients ${ }^{32}$.

A group of Kenyan medicalexperts ${ }^{33}$ had recommended that CBD agents should provide only low dose pills to new clients because they cannot provide a full physical examination prior to use. Although no agent had only high dose pills in stock, with the exception of agents from the MOH/GTZ programme (who had only low dose pills), agents from the other programmes stocked both low and high dose pills. The proportions of agents found to have specific brands of pills are as follows: discuss the issue of whether a mandatory physical examination was a pre-requisite to oral contraceptive provision by $\mathrm{CBD}$ agents. After much debate, the Symposium arrived at the conclusion that CBD programmes should provide "only the low dose OCs", and when this is done "physical examination was not mandatory prior to use" (Ndavi 1993:3). These recommendations were to be sent to the Director Of Medical Services and to the Director of NCPD "for immediate implementation nationally," but no action has yet been taken. 
Low dose pills:

Microgynon (96\%)

Microlut (62\%)

Logynon $(20 \%)$

Trinodiol (13\%)

Nordette $(10 \%)$

Marvelon (9\%)
High dose pills:

Eugynon (56\%)

Neogynon $(28 \%)$

Almost 80 percent of the CBD clients interviewed said that the agent discussed methods other than the one they chose, and told them that they could change the method if they wanted to, and 90 percent said that they received their preferred method ${ }^{34}$. Although asking clients about these issues may be prone to some courtesy bias, these data suggest that clients either know what they want when they meet with a CBD agent and/or are given a choice of more than one method.

\section{d) Provider-client information exchange}

Two indicators were used to measure whether the agents tried to understand their clients' reproductive intentions. More than three quarters of the CBD clients reported that they were asked why they wanted to use family planning. Thus, it would appear that most CBD agents are trying to find out, at least broadly, theirclients' reproductive intentions. Secondly, 75 percent of clients reported that the agent asked them about their medical history, indicating that some form of screening for inappropriate methods is also taking place.

A series of questions were asked to assess the information provided when clients were first given their current method. The majority said that they were:

C shown how to use the method they received (90 percent),

C told what to do if they experienced problems with the method chosen (83 percent),

C informed that they could change the method ( 83 percent),

C informed about the possible side effects of their method (73 percent),

C satisfied overall with the information provided to them (83 percent).

The CBD agents were asked through open-ended questions to spontaneously describe the information they normally collect from and give to new pill users. Although these results do not necessarily describe what the agents do in every situation, they do give some indication of what issues the agents feel are important when counseling pill clients. Their responses, as shown below, suggest that the agents put most emphasis on how to use the pill and less on establishing a client's needs or informing her of the side effects and their management: 
C 29 percent reported that they ask about the client's reproductive intentions ${ }^{35}$

C 29 percent asked about breastfeeding status

C $\quad 57$ percent said they instructed clients on how to use the pill

C 25 percent mentioned discussing possible side effects

C 19 percent mentioned how to manage the side effects.

It is helpful for agents to have some IEC materials and other aids which they can use during counseling. Most programmes provide some materials to their agents (see Figure V.1), although none of the NCCS agents had IEC materials at the time of the interview. The FLPS programme agents were the best supplied, with over three-quarters of them having charts and pamphlets, anatomical models and other items.

\section{e) Technical competence}

\section{i) Training}

All programmes use the national CBD training curriculum and provide formal preservice training to new CBD agents, usually for about two weeks. In situations where a CBD agent has left the programme, the replacement is normally trained by the supervisor "on the job" before receiving formal training the next time it is held. The FPAK, MYWO, FLPS and the two NCC programmes have annual refresher courses, while the MOH/GTZ and CHAK programmes have biannual refresher courses; 79 percent of the agents had attended a refresher course since their basic training.

AlthoughSTD/HIV preventionand management are part of the national CBD training curriculum, 15 percent of the agents said that they had not received any formal training on these topics. When asked whether they were satisfied with their level of training, 40 percent felt that it was inadequate for providing family planning. Of those who had been trained in STD/HIV, one-half felt it was not adequate. For example, almost all agents stated that although they had been trained in HIV/AIDS, gonorrhea and syphilis, the vast majority had not been taught about chlamydia, candida, trichomoniasis, or chancroid. 


\section{ii) Assessing medical history and use of a checklist}

More than three quarters of the pill users served by a CBD agent said that their medical history had been taken, although this is a slightly lower proportion than those receiving their method from a clinic (84 - 98 percent). All CBD agents are expected to use a checklist for screening new pill clients, yet almost one-quarter of the agents did not have a pill screening checklist with them on the day of the interview; most of the agents not having a checklist, and not mentioning that they use one, were from the CHAK and NCCS programmes. About two-thirds of the agents reported that they ask new pill clients if they have missed their last period.

\section{iii) Knowledge of correct pill and condom use}

All CBD agents were asked a few questions on how the pill and condom should be used. Only 50-60 percent of agents knew what a client should do if she forgets to take the pill for two or three consecutive days. Although the proportion knowing the appropriate pill use for breastfeeding mothers was high ( 87 percent), only 60 percent knew about the preconditions for a breastfeeding mother to use the progestin-only pill.

The agents knowledge of possible side effects of the pill was adequate, in that approximately half could mention the major side effects (e.g. spotting, mild nausea, headaches, dizziness, weight gain), although only eight percent mentioned breast tenderness. When asked to state the kind of client they should not provide the pill to, or provide with caution due to medical reasons, the agents provided a range of answers, a number of them incorrect ${ }^{36}$. When asked about contraindications for the pill, only varicose veins ( 80 percent) and hypertension ( 71 percent) were mentioned by more than half of the CBD agents.

Although all CBD agents know how to dispose of a used condom, full knowledge of how to use the condom properly was poor (Figure V.2). In addition, the proportion of CBD agents' with knowledge about the appropriate use of contraception for clients who are at high risk of STI/HIV infection was low. Only 44 percent of the agents said that a client using the pill and who appears to be at high risk of infection should also use condoms.

\section{Figure V.2 Proportion of 199 agents with correct knowledge of condom use}

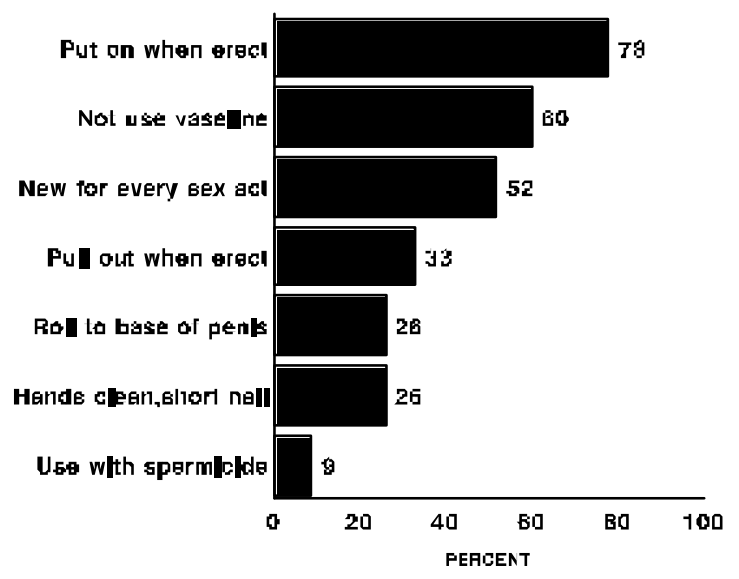

36 Examples include women who have had an abortion or miscarriage, women who have had a caesarian, and women with several sexual partners. 
Significant differences exist between the programmes in terms of their agents' knowledge of pill and condom use, primary and secondary contraindications and side effects of the pill. However, these differences varied from one item to another, that is, agents from programmes performing well in one aspect often had an average or poor performance on another item. As the training for all programmes is based on the same national CBD curriculum, one would expect that any deficiencies in CBD knowledge would be systematic across all programmes, but this variability suggests that the way the national training curriculum is adapted and taught is different for each programme.

An attempt was made to calculate a composite score for the level of technical knowledge among the CBD agents for each programme. These scores were based on the percentage of the programme's agents who had provided correct answers to each question $^{37}$. As Figure V.3 indicates, the agents in the FLPS programme had the highest scores for both pill and condom use, while agents from the CHAK and $\mathrm{MOH} / \mathrm{GTZ}$ programmes scored lowest overall. There were not large differences between the programmes, however, and the overall levels of the scores would seem to be rather disappointing. Consequently, each programme should review their training activities in light of these findings and focus on strengthening those aspects in which their agents are weakest.
Figure V.3 Composite scores for technical knowledge on pill and condom use by programme

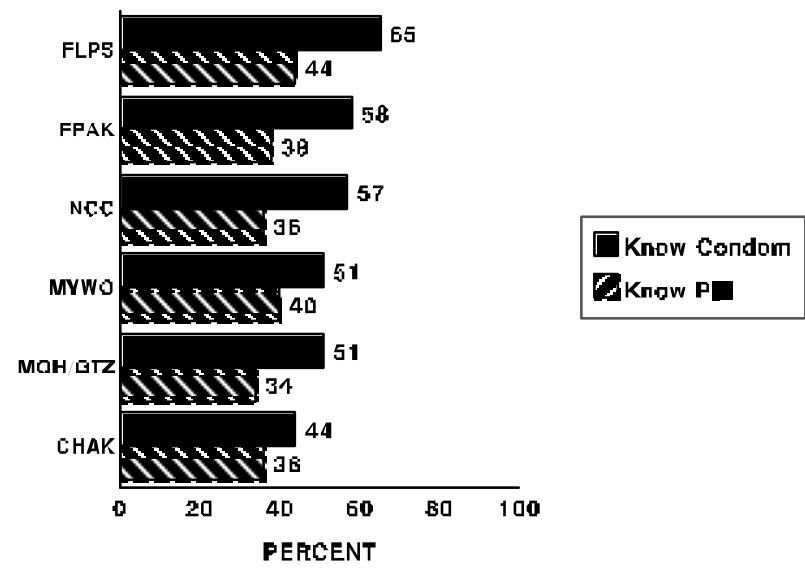

\section{f) Ensuring continuity of use}

Two indicators were used to measure the ability of the CBD agents to ensure that their clients could continue to use family planning, whether they have contraceptive supplies and whether clients were told when to return for resupply. On the day of the interview, most agents had supplies of pills and condoms, but very few had spermicides because of a nationalshortage at the time. One third of the agents reported that they had run out of supplies at some time in the previous 6 months, although there is some variation across programmes and by method. While 35-43 percent of agents in the CHAK, FPAK, MYWO and NCCS programmes had a stock-out, only 11 percent of agents in the FLPS programme and 25 percent in the MOH/GTZ programme reported this problem. Stockouts were reported more frequently for combined pills (21 percent of agents) than for condoms (9

37 The score was obtained by adding up all the correct responses mentioned by individual CBD agents and calculating the average score for each programme. 
percent), jelly/foam tablets ( 8 percent) and Microlut pills (3 percent). For spermicides, the low stock out rates reported reflects the fact that some agents had so rarely had any spermicides that they didn't consider it a method they normally provide, and so this rate applies only to those who had some supplies in the past.

The vast majority of clients reported that they had been given a return visit date. Whether these dates were adhered to, however, is not known. Interviews with programme staff indicated that all programmes, except the $\mathrm{MOH} / \mathrm{GTZ}$ programme, has a mechanism for tracking referrals made by agents to clinics. This is done either by the agent's supervisor visiting or checking with the clinic on those clients referred, or by using a referral form which the client takes to the clinic, gets signed by the clinic staff after receiving the service, and then gives to the CBD agent. However, it was not possible to assess how effectively these systems are used.

\section{g) Appropriateness and acceptability of services}

All contraceptive method users were asked if they knew of any other source for their current method, and if they did, why they chose not to use it. Only six percent of the current male and female users who obtained their method from a clinic said that they knew of a CBD agent as another source for their method. Less than ten percent of these female respondents who knew of a CBD agent said that they didn't use the agent because they didn't like the person or because they thought they provided poor quality services. For the male respondents, cost, the time CBD agent is available to serve clients and lack of anonymity were three reasons (each mentioned by 10 percent of male respondents) for not using the CBD source. 


\section{VI: CONCLUSIONS AND RECOMMENDATIONS FOR STRENGTHENING CBD PROGRAMMES}

This study has collected information on several different aspects of CBD programmes in Kenya. This information is directly relevant to the program managers and policy makers responsible for implementing and coordinating the CBD programmes in Kenya, and to the donor and technical assistance agencies supporting these efforts. Several of the implementing organizations have already started to use the information (see section VII) to identify their programmes strengths and weaknesses and to guide their planning for the future. This section presents some recommendations drawn from the data collected and that could be used when making decisions about future planning, funding and technical assistance for CBD programmes in Kenya, and probably also in other countries in the region.

It should be emphasized that no one programme is strongest or weakest in all elements, which probably reflects the fact that all programmes have evolved over time and adjusted to the environments in which they operate, the resources available and the organizational structures in which they operate. Overall it can be concluded that:

C Agents from the church-based CHAK programme are known by the largest proportion of community members in their catchment areas and provide contraceptives to more community members than the other programmes. All the urban-based programmes are weak in this regard; amongst the rural-based programmes, the $\mathrm{MOH} / \mathrm{GTZ}$ programme is the weakest.

C The urban-based NCCFP programme relies on full-time paid CBD agents who have the highest output per CBD agent. Amongst the rural-based programmes with part-time agents, FPAK provides its agents with moderate remuneration and has the highest output per agent and is the most cost-effective programme. The MOH/GTZ programme gives no remuneration and few incentives and has the lowest productivity per agent, but its cost-effectiveness ratios are not too dissimilar to the FPAK programme.

C Two rural-based programmes (CHAK, MYWO) and one urban-based programmes (FLPS) are amongst the least cost-effective programmes.

C The small urban-based FLPS programme and the large rural-based FPAK programme have the highest average scores for quality of care.

C A programme's cost-effectiveness is a measure of its output performance and effective use of resources. FPAK is the most cost-effective model although its cost ratios are not largely different from those of the NCCS and NCCFP. 
Some specific recommendations are as follows:

\section{a) Strengthening the role of $\mathrm{CBD}$ agents as providers of information and services}

CBD agents are known to only half the population in their catchment areas, and yet if people know about them then they are much more likely to use them for obtaining information and services. They are least effective in areas with low contraceptive rates. CBD agents are seen by community members as acceptable sources of information about STIs and HIV/AIDS and other reproductive health issues, and as potential sources of information for the youth. Most CBD agents focus mainly on providing services to married women with children and to older men, and not on addressing the needs of young unmarried people, and especially unmarried women without children.

C Greater publicity about the presence of a CBD agent and their work in a community would increase the number of people who use them for information and services.

C Agents located in areas with low contraceptive prevalence rates should be given extra attention and support by the programme as it has proven harder for them to provide services in such environments.

C CBD agents should be trained more thoroughly in other reproductive health issues and encouraged to act as sources of information for other community members, especially the youth.

C National and programme policy guidelines should spell out clearly the need to meet the reproductive health needs of youth and especially of individuals and couples looking to delay their first birth.

C CBD programmes should train their agents in the implications of adolescents' sexual behavior and in the gender factors surrounding contraceptive use and sexual health.

C CBD programmes should have more males as agents, and also encourage their agents to meet with males directly, either individually or through their wives. They should also be prepared to talk more about vasectomy to couples looking to limit their family size.

\section{b) Recordkeeping and reporting}

Although agents are expected to provide both family planning and other reproductive health information and services, not all agencies require their agents to keep records of all family planning activities, very few record the non-family planning activities, and none record information-giving activities. There is also poor correspondence between the records kept by individualCBD agents and those at the programme offices in some programmes. 
C Recordkeeping systems should be reviewed for the relevance of the data collected and a uniformrecording and reporting system be developed and adapted. Particular attention should be paid to recording and reporting the many non-family planning activities which CBD agents undertake, including generalinformation-giving on family planning and other reproductive health issues. This is particularly important in areas with low contraceptive prevalence and/or poor utilization of other reproductive health services.

C For family planning services provided, agreement should be reached on a uniform definition of a new user. It is suggested that it be a new "acceptor", and a category of "continuing" user be used for those who are new to the CBD agent.

C Following discussions of the study findings with representatives from several CBD organizations, the following performance and monitoring indicators should be considered as standard to ensure that programmes can be evaluated and compared:

- volume of new FP clients by method and sex;

- volume of revisit/continuing clients by method and sex;

- volume of effective and non-effective FP referrals by method;

- volume of FP information / communication activities by type (e.g. individual/group), and by number of people contacted;

- volume of non-FP (e.g. MCH, PHC, STD/HIV, sexuality) information / communication activities by type;

- volume of non-FP referrals for services by type.

C Each programme should review its reporting procedures so that summary records kept at all levels are identical.

C Formulate national guidelines to systematize the referral of clients by CBD agents to clinics and to record and report on these activities.

C Include referralclients (for both FP and non-FP services) and CYP generated by FP referrals as performance indicators.

\section{c) Supervision}

A strong supervisory system was shown to be a key determinant of the performance of CBD agents. Agents' individual contact with their immediate supervisor is not only important for motivation, but also helps the supervisor to monitor agents' contraceptive stock needs and to forecast required quantities of contraceptives to avoid unnecessary contraceptive stock-outs. Consequently, ways in which the existing supervisory systems can be strengthened and maintained need to be addressed. Some suggestions are: 
C have full-time field-based staff as the immediate supervisor for CBD agents;

C ensure and maintain a monthly supervisory schedule with fixed dates for individualmeetings with agents;

C develop and implement a supervisory checklist to guide supervisors;

C encourage notes to be kept of the supervisory visit by both the supervisor and the agent for monitoring future activities.

\section{d) Improving programme cost-effectiveness}

Agent remuneration on its own does not necessarily make a programme more or less costeffective, and it does not strongly influence agent performance, but it does improve job satisfaction. Most programmes appear to be able to achieve similar cost-effectiveness ratios. Those with the highest ratios have the lowest proportion of their budgets allocated (theoretically at least) to contraceptives, suggesting that they have the capacity to expand the volume of services delivered without significantly increasing the infrastructure needed to do so.

C The two programmes which do not currently remunerate their agents (MOH/GTZ and NCCS) should consider introducing a moderate level of remuneration as this may increase agent satisfaction and possibly reduce the likelihood of agents dropping out early.

C The two programmes with the highest cost-effectiveness ratios (MYWO and FLPS) should look for ways to increase the volume of service provided within their existing structures.

\section{e) Improving service quality}

Clients appear to be satisfied with the service received, although the quality of care provided varied across programmes due to differences in agent knowledge and practices. Some actions could be taken to improve the quality provided.

C Spermicide supplies should be better maintained and agents should continuously have supplies of both low-dose combined and progestin-only pills.

C Basic and refresher training on family planning should reinforce the need to informclients about possible side effects and their management.

C Supervisors must ensure that agents keep the pill screening checklist with them at all times and use it with every new client. 
C The national training curriculum and the training departments of the CBD programmes must strengthen their coverage of other health issues, especially the signs and symptoms of RTIs/STIs, correct breastfeeding and management of diarrhoea and malaria. The importance of discussing family planning and other reproductive health issues in the context of human sexuality should be emphasized during training, and agents given suggestions and support in how best to do this.

\section{In conclusion:}

A cost-effective CBD programme in Kenya is one that has:

$<\quad$ promotional strategies to ensure that its agents and their services are widely known in their catchment areas;

$<\quad$ a supervisory system that reaches agents monthly and focuses on the quality of service they provide;

$<\quad$ high quality basic training with frequent refresher courses that reinforce existing skills and occasionally introduce new skills;

$<\quad$ specific motivational strategies in place in the low CPR areas of coverage;

$<\quad$ provides a moderate remuneration and varied non-financial incentives to its part-time agents to maintain their commitment. 


\section{VII: DISSEMINATION AND UTILIZATION OF STUDY RESULTS}

The study results were formally presented to an audience of programme managers, policy makers, donors and technical assistance organizations at a national dissemination seminar in March 1996. Subsequently, several of the managers requested that the data be disaggregated for their specific programmes so that they could learn more about their strengths and weaknesses and discuss the findings with their colleagues. This was done, and individual workshops have been held to date with FPAK, CHAK, the NCC Slum Project and the NCCFP Project:

These workshops were attended by the programme directors, CBD programme managers and supervisors from both the headquarters and local levels for each programme. The findings for each programme were presented to the participants by some of the programme staff in collaboration with the study's Principal Investigator. The results were presented under four broad headings:

C The role of CBD agents as family planning, reproductive health and $\mathrm{MCH} / \mathrm{PHC}$ service providers;

C Programme outputs, record keeping and reporting and supervision

C Costs, cost-effectiveness and sustainability

C Quality of care provided.

At each workshop the participants divided into small groups and were given the task of identifying and commenting on the possible reasons for each of the study's major findings for that particular programme. In addition, they were requested to make policy and programmatic recommendations that would improve the programme's performance on the observed weaknesses. Further, the groups were required to identify the person/persons responsible for implementing each recommendation, and the time frame in which this would be done.

The study has also attracted attention internationally as the wide range of programmes and experiences in Kenya provide a wealth of information for those in other countries and in other regions seeking to strengthen existing or introduce new CBD programmes. This report is being distributed widely within Africa and beyond, and the possibility of publishing the results in relevant journals is being explored. 


\section{REFERENCES}

Barasa, J. and Kanani, S. 1991. "An Inventory Study Of Community Based Distribution Of Family Planning Services". An Unpublished Report Prepared For NCPD and United Nations Fund For Population Activities (Kenya Office).

Bruce, J. 1990. "Fundamental elements of the quality of care: A simple framework." Studies In Family Planning 21, 2:61-91.

Kak, Lily P. and S. Narasimhan. 1992. "The Impact Of Family Planning Employment on Field Workers' Lives: A strategy For Measuring Empowerment", Working Paper Number 1, CEDPA, Washington, USA.

The EVALUATION Project. 1993. "Indicators of Quality of Care in International Family Planning Programs", Service Delivery Working Group, Tulane University, New Orleans, Louisiana.

FPAK and The Population Council. 1994. "Increasing Male Involvement In The Family Planning Association (FPAK) Family Planning Program", Africa Operations and Technical Assistance Project, The Population Council, Nairobi, Kenya.

Janowitz, B. and J. Bratt. 1994. Methods for Costing Family Planning Services, UNFPA and FHI, Raleigh, NC.

Lewis, G. , N. Keyonzo and P. Mott. 1992. "Community-Based Family Planning Services: Insights From The Kenyan Experience." Paper presented at the Population Association Of America Annual Meeting held at Denver, Colorado, April 28 - May 2, 1992.

Mundy, J. and I. Askew. 1994. "Current Experiences With Community-Based Distribution Of Family Planning In Kenya". A Review Prepared For USAID/Kenya." The Population Council: Nairobi, Kenya.

MYWO. 1995. MCH/FP CBD Family Planning CBD Project Catchment Area Survey, Summary presented at a Dissemination Workshop, Limuru, Kenya.

NCPD, CBS, and Macro International. 1994. Kenya Demographic \& Health Survey 1993. Calverton, Maryland: NCPD, CBS, and MI.

Phillips J. and W. Green. 1993. "Community Based Distribution of Family Planning In Africa: Lessons From Operations Research". The Population Council, New York, USA.

Reynolds, J. and K. Gaspari. 1985. Cost-Effectiveness Analysis, PRICOR Monograph Series: Methods Papers 2, URC, Chevy Chase, Maryland.

Ross, J., D. Lauro, J. Wray, \& A. Rosenfield. 1987. "Community Based Distribution, " in R. Lapham \& G. Simmons (eds.), Organizing For Effective Family Planning Programs, Washington D.C.:National Academy Press. 


\section{APPENDIX I: Descriptions of CBD Programmes}

\section{a) The Family Planning Association of Kenya (FPAK) Programme}

The FPAK is the oldest NGO providing family planning services in Kenya, formed in 1957. In addition to providing family planning services at its clinics, FPAK was given primary responsibility for providing FP information and education by the Government following the launch of the national family planning programme in 1967. In 1982, FPAK added CBD agents to its group of family planning field educators. By 1994, FPAK had the largest geographicalcoverage of any CBD programme, but only the third largest number of CBD agents: with over 700 active CBD agents, FPAK covered seven of the eight administrative provinces ${ }^{38}$ in Kenya, 18 districts $^{39}$ and 40 divisions. The agents are identified initially by community leaders and interviewed by a panel of FPAK staff and community leaders, but they are supervised solely by FPAK staff. The agents are provided with a uniform and a monthly allowance of Ksh. 500. The agents refer their clients to an FPAK clinic (static or mobile) if one is located locally; if not, they refer to the nearest clinic providing family planning services.

\section{b) The Maendeleo Ya Wanawake Organization (MYWO) Programme}

MYWO, an organization with a mandate to improve the socioeconomic status of women in Kenya was started in 1952. The organization operates through women groups at the community level, and has elected officials at both the grassroots and national levels. These are elected to office by the members of the organization, who are all women. With the goal of providing services to women groups in rural areas, the MYWO CBD programme was initially started as a Maternal Child Health and FP (MCH/FP) motivation pilot project in April 1979 (Lewis et al, 1992). In 1983, the FP Motivators were trained to provide non-clinicalmethods, thereby launching a full CBD programme. By 1994, the MYWO CBD programme had the second highest geographical coverage and the second largest number of CBD agents. With 1,239 active CBD agents selected mainly through the women groups in various parts of the country, the programme covered five provinces, 12 districts ${ }^{40}$ and 32 divisions. Since MYWO has no clinics of its own, the organization's CBD agents refer clients requiring other services to the nearest clinic. The agents get their contraceptive supplies and are supervised directly from the organization's offices at the divisionallevel. The agents are provided with a monthly allowance of Ksh 400.

FPAK is the only rural based model that has a site in the urban area. Surprisingly, its Kibera/Kasarani site in Nairobi, which had 30 CBD agents in 1994, was not the best either in total volume of clients served and contraceptives distributed, or in output per CBD. FPAK sites which had the same or fewer number of CBD agents and are located in the rural areas had higher output than this site. 


\section{c) The Christian Health Association of Kenya (CHAK) Programme}

CHAK is an umbrella association with responsibility for managing health facilities owned by 29 Protestant denomination organizations. These facilities provide about 20 percent of all health care services in the country. By 1994, 21 of CHAK's static clinics were offering family planning services. The organization's CBD programme was established in 1989 and by 1994 was located in nine sites linked directly with nine of the CHAK clinics. The programme covered 5 provinces, 9 districts ${ }^{41}$ and 20 divisions. The CBD agents work part-time and are recruited through the churches in the catchment areas. They are provided with a small monthly allowance of about Ksh 100 which is given after about four months. However, since the member clinics are not owned by CHAK, each can make its own decision about paying CBD agents, and some do not pay anything at all.

\section{d) The Ministry of Health/GTZ (MOH/GTZ) Programme}

The Ministry of Health, charged with the responsibility of providing health services including family planning services nationwide, did not start a CBD programme until 1991. The programme's CBD agents are identified by their communities through the help of local community leaders, and are linked directly with the local $\mathrm{MOH}$ clinic for both supervision and logistic support. Although the programme had the highest number of active CBD agents $(4,158)$ in 1994, the programme covered only two provinces, six districts ${ }^{42}$ and about 538 sub-locations, being linked with $110 \mathrm{MOH}$ clinics. This reflects a significantly different approach to CBD than that taken by the other rural-based programmes. In 1994, the FPAK model had one CBD agent cover a sub-location ${ }^{43}$, and the MYWO and CHAK programmes had approximately three to five CBD agents per sub-location, whereas the $\mathrm{MOH} / \mathrm{GTZ}$ programme's target of one CBD agent per 40 households gives the highest concentration of agents in a sub-location.

The districts covered were: Bungoma, Kericho, Kiambu, Nyambene (in former Meru), Nyeri, Kakamega and three new districts which formerly comprised the South Nyanza districts (Migori, Kuria and Homa-Bay). 


\section{e) The Family Life Promotion and Services (FLPS) Project}

The FLPS Project is the smallest of all the organizations implementing CBD programmes included in the study. The organization was started in 1988 in Nairobi and with the objective of providing family planning and reproductive health services through CBD and static clinic approaches. By 1994, FLPS had 73 agents located in two urban sites, Nairobi(53 agents), and Kisumu Town (20 agents, started in late 1993). The CBD agents in these sites are linked to an FLPS static clinic for supervision and logistics. In addition, they refer their clients for clinical methods and STD screening and treatment to these and other clinics. The focus of the FLPS programme is workers in the informal sector, mainly those working in market centers and commercial sex workers. It also covers housing estates surrounding the markets. In Nairobi, coverage extends across three Divisions (Central, Makadara, Pumwani). The agents receive a monthly allowance of between Ksh.450 and Ksh.600. To recruit new agents, the organization advertises through the local administration and the candidates go through an interview to be selected.

\section{f) The Nairobi City Council (NCC) Projects}

The NCC is responsible for providing health, education and socialservices to the city. Of the two CBD projects implemented by the NCC, the NCC Family Planning (NCCFP) Project was the first to be developed. Started in 1987, by 1994 the NCCFP project had 44 full-time, employed CBD agents (earning about Ksh. 2020 per month) attached to 24 NCC clinics which cover all eight Divisions in the city. The NCCFP CBD agents serve the communities surrounding the clinics, but also have a specialfocus on factories. These agents get their contraceptive supplies and are supervised from these clinics.

The NCC Slum (NCCS) Project was started in 1989 and had 257 part-time, unpaid agents based in seven slum areas by 1994. The agents are also attached to the NCC clinics for supply of contraceptives, but not supervision; they are supervised from the Slum Project headquarters. These CBD agents, who are recruited through local communities and their leaders, are assigned to specific villages within the slum areas, although there is overlap in some areas with coverage by the NCCFP agents. 


\section{APPENDIX II: Calculating programme costs and sensitivity analysis}

\section{a) Capital costs}

Capital costs describe those items in a programme which are purchased once only and have an expected useful life of more than one year. For this study they were categorized as: -

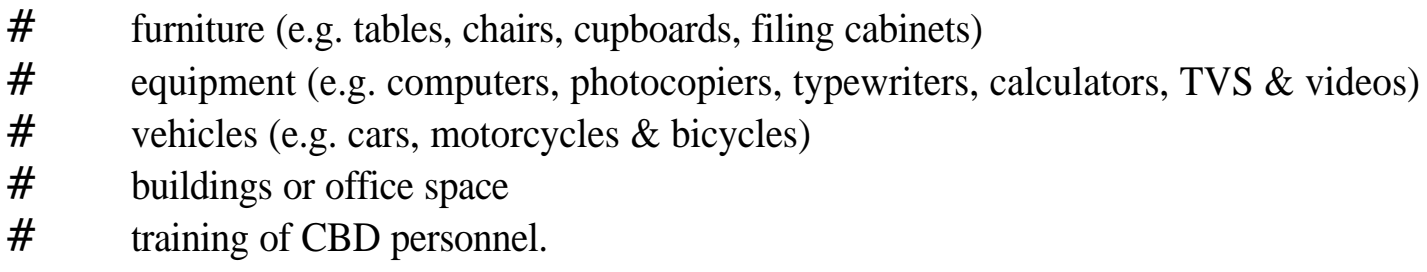

Because capital costs have an expected useful life of more than one year, it was necessary to calculate the proportion of the actual cost for an item that could be allocated to its use in 1994; this process is known as annualizing the cost. Two procedures were used to calculate the annualized costs for 1994:

C the Straight Line Depreciation (SLD) formula assumes that an item is used equally over its total expected useful life, and so an item's annualized cost is its actual purchase price divided by years of expected useful life;

C the Double Declining Balance (DDB) formula assumes that an item is used at a higher rate during the initial years of its expected useful life and that its use declines over time. This is a complex calculation ${ }^{44}$ and so the Lotus 1-2-3 DDB computer programme was used.

These capital cost items were assigned different durations for their expected useful life ${ }^{45}$ :

C all furniture items were estimated to have an expected useful life of 10 years, except filing cabinets which were assigned five years;

C all vehicles were estimated to have a useful life of seven years, motorcycles five years, and bicycles three years;

C all office equipment, including computers, were assigned a useful life of three years;

C the basic training for CBD personnel is a one-time activity, but refresher courses are mounted occasionally by most programmes, and so these have been added to the basic training costs to give a total value for the training category. For costing purposes, the skills acquired during

\footnotetext{
44 The formula includes the actual purchase price of the item, its expected useful life, its "salvage" value at the end of its useful life (assumed to be zero), and the number of years that the item has been used. the expected useful life is used rather than the actual duration of use.
} 
all these training sessions are assumed to be used up during the overall life of the project, and therefore all training activities have been treated as capital cost inputs. Training costs are probably the most difficult capital cost category to estimate accurately, given that the amount of training provided (and thus the costs incurred) is related to the expected age of the CBD programme. The oldest CBD programme (FPAK) has been in existence for more than 15 years, and many of the originalCBD agents are still working, an so it was proposed that for this analysis the expected useful life for all training activities could be up to 15 years. Given that there will be an attrition of trained agents over time and that most training occurs at the beginning of a CBD programme, the assumptions of the DDB formula would seem to be more appropriate for this cost category.

\section{b) Recurrent costs}

Recurrent cost items comprise of those items which are purchased regularly as they have useful life of less than one year. For this study the categories include: -

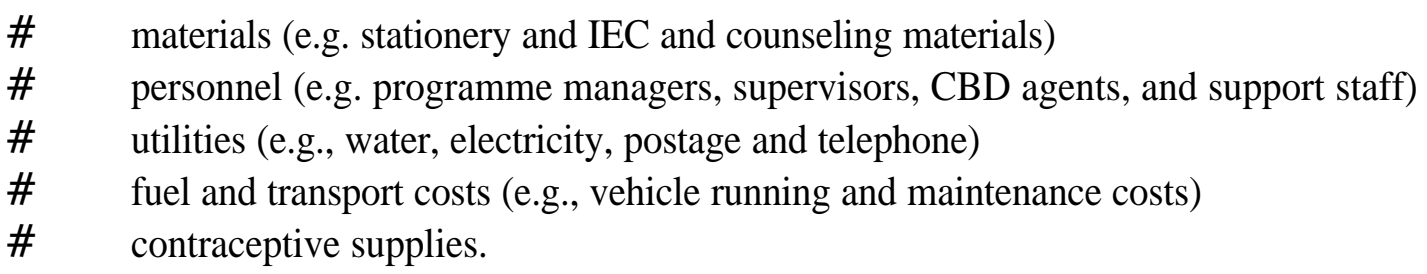

Because recurrent costs are "consumed", usually within one year of their purchase, and so need to be purchased regularly, their value will vary annually depending on the volume of items consumed during the year. For this analysis, the actual volumes of recurrent items consumed in 1994 were obtained from each organization and were then valued at 1994 prices; where 1994 prices were unavailable, a factor of 0.712 (based on the official inflation rate) was used to deflate 1995 prices to 1994 prices. In costing each of the categories given above, only the appropriate proportion of each item allocable to the CBD programme was included (i.e. the joint cost); this proportion was calculated through interviews with knowledgeable staff fromeach organization. For contraceptive commodities, the theoretical purchase price for the CBD programmes was calculated using the actual cost of the commodities to the donor organization. The price for pills and condoms was calculated using the price which USAID pays, as it is the major supplier of these commodities in Kenya, whereas for spermicide creams and jellies the IPPF price was used as this organization is the major supplier.

\section{c) Sensitivity analysis}

The assumptions given above were varied slightly to test the sensitivity of the results to any possible inaccuracies in making the assumptions. The most difficult assumption was regarding the expected useful life of CBD training, and so three different project life spans of 10,15 and 20 years have been used. Both the DDB and SLD formulas for capital cost annualization have also been considered. Thus five further estimates were calculated and are shown in the table overleaf. 


\begin{tabular}{||c|c|c|c|c|c|c|c||}
\hline Programme & CHAK & MOH/GTZ & FPAK & MYWO & FLPS & NCCS & NCCFP \\
\hline Total costs & $11,526,656$ & $33,490,062$ & $33,779,481$ & $39,957,124$ & $3,342,602$ & $9,005,204$ & $6,224,171$ \\
\hline Sensitivity analyses: & & & & & & \\
$(\mathbf{a a )}$ & $11,527,141$ & $33,569,507$ & $33,470,196$ & $38,916,670$ & $3,340,045$ & $9,008,510$ & $6,209,737$ \\
$(\mathbf{c a})$ & $11,517,982$ & $33,419,322$ & $33,835,039$ & $40,098,564$ & $3,340,495$ & $9,000,460$ & $6,221,834$ \\
$(\mathbf{a b})$ & $11,558,833$ & $32,838,499$ & $33,672,610$ & $39,459,169$ & $3,424,462$ & $8,954,073$ & $6,223,869$ \\
$(\mathbf{b b})$ & $11,558,349$ & $32,759,054$ & $33,981,895$ & $40,499,623$ & $3,427,019$ & $8,950,767$ & $6,238,303$ \\
$(\mathbf{c b})$ & $11,549,674$ & $32,688,314$ & $34,037,452$ & $40,641,063$ & $3,424,911$ & $8,946,023$ & $6,235,966$ \\
\hline
\end{tabular}

This estimates are based on the following considerations. Estimates $a a$ and $c a$ represent costs computed using the DDB procedure for the capital costs, with 10 and 20 years respectively of expected useful life for the training costs (option ba represents using the DDB procedure and a 15-year project life for training, i.e the estimates given in section IV). Estimates $a b, b b$ and $c b$ represent costs calculated using the SLD procedure for capital costs and 10, 15, and 20 years respectively of programme life for the training costs.

This sensitivity analysis shows that these alternative costing assumptions do not result in significant differences in the total programme costs, suggesting that the original assumptions used are quite robust. The analysis also suggests that variation in programme ages on the annualization of training costs is nota problematic issue, except possibly for the MOH/GTZ programme for which CBD training is a major proportion of the budget and so variations will have a larger impact. 